\title{
lonic silver functionalized ovine forestomach matrix - a non-cytotoxic antimicrobial biomaterial for tissue regeneration applications
}

Tanvi Karnik, Sandi G. Dempsey, Micheal J. Jerram, Arun Nagarajan, Ravindra Rajam, Barnaby C. H. May and Christopher H. Miller

\begin{abstract}
Background: Antimicrobial technologies, including silver-containing medical devices, are increasingly utilized in clinical regimens to mitigate risks of microbial colonization. Silver-functionalized resorbable biomaterials for use in wound management and tissue regeneration applications have a narrow therapeutic index where antimicrobial effectiveness may be outweighed by adverse cytotoxicity. We examined the effects of ionic silver functionalization of an extracellular matrix (ECM) biomaterial derived from ovine forestomach (OFM-Ag) in terms of material properties, antimicrobial effectiveness and cytotoxicity profile.
\end{abstract}

Methods: Material properties of OFM-Ag were assessed by via biochemical analysis, microscopy, atomic absorption spectroscopy (AAS) and differential scanning calorimetry. The silver release profile of OFM-Ag was profiled by AAS and antimicrobial effectiveness testing utilized to determine the minimum effective concentration of silver in OFM$\mathrm{Ag}$ in addition to the antimicrobial spectrum and wear time. Biofilm prevention properties of OFM-Ag in comparison to silver containing collagen dressing materials was quantified via in vitro crystal violet assay using a polymicrobial model. Toxicity of ionic silver, OFM-Ag and silver containing collagen dressing materials was assessed toward mammalian fibroblasts using elution cytoxicity testing.

Results: OFM-Ag retained the native ECM compositional and structural characteristic of non-silver functionalized ECM material while imparting broad spectrum antimicrobial effectiveness toward 11 clinically relevant microbial species including fungi and drug resistant strains, maintaining effectiveness over a wear time duration of 7-days. OFM-Ag demonstrated significant prevention of polymicrobial biofilm formation compared to non-antimicrobial and silver-containing collagen dressing materials. Where silver-containing collagen dressing materials exhibited cytotoxic effects toward mammalian fibroblasts, OFM-Ag was determined to be non-cytotoxic, silver elution studies indicated sustained retention of silver in OFM-Ag as a possible mechanism for the attenuated cytotoxicity.

Conclusions: This work demonstrates ECM biomaterials may be functionalized with silver to favourably shift the balance between detrimental cytotoxic potential and beneficial antimicrobial effects, while preserving the ECM structure and function of utility in tissue regeneration applications.

Keywords: Chronic wounds, Silver, Biofilm, Cytotoxicity, Antimicrobial, ECM (extracellular matrix), Ovine forestomach matrix (OFM)

\footnotetext{
* Correspondence: Christopher.Miller@aroabio.com

Aroa Biosurgery, 2 Kingsford Smith Place, PO Box 107111, Auckland Airport,

Auckland 2150, New Zealand
}

(c) The Author(s). 2019 Open Access This article is distributed under the terms of the Creative Commons Attribution 4.0 International License (http://creativecommons.org/licenses/by/4.0/), which permits unrestricted use, distribution, and

reproduction in any medium, provided you give appropriate credit to the original author(s) and the source, provide a link to the Creative Commons license, and indicate if changes were made. The Creative Commons Public Domain Dedication waiver (http://creativecommons.org/publicdomain/zero/1.0/) applies to the data made available in this article, unless otherwise stated. 


\section{Introduction}

Collagen-based biomaterials that serve as scaffolds for tissue regeneration have been widely adopted for various clinical applications, particularly in the management of acute and chronic wounds (i.e., venous and diabetic ulcers). However, the risk from microbial challenge presents a potential complication to the use of these products. Topically applied collagen presents a substantial external surface area which is exposed to sources of microbial contamination such as the patient environment, wound contaminants and commensal flora at the wound periphery [1]. Additionally, chronic wounds are associated with a high incidence and degree of microbial colonization, with consensus indicating all chronic wounds are colonized [2, 3]. These combined microbial challenges present a significant risk of microbial colonization. Collagen wound dressings while beneficial for wound healing also provide a favourably porous, moist and nutritious substrate for microbial colonization $[4,5]$. As microbial growth rates greatly exceed that of mammalian cells, microbial colonization of dressing materials prior to patient cell infiltration reduces the effectiveness of the dressing and potentially acts as a nidus for local wound and subsequent systemic infection [6-8].

Contaminating microbes may also form biofilms in the wound. These complex and often polymicrobial (constituting multiple species) communities of microorganisms in various metabolic states are fortified in a structured extracellular polymeric matrix of polysaccharides, proteins and nucleic acids. Microbial populations in biofilm are highly resistant to inactivation by chemical and environmental stressors such as disinfectants, antimicrobial/antibiotic agents and immune response [9]. The presence of biofilm in the wound is associated with adverse effects such as chronic inflammation [10], delayed healing [11], increased risk of infection [9, 12] and increased recurrence or complications [13]. In particular, chronic wounds are almost ubiquitously affected by biofilm, with meta-analysis indicating the prevalence of biofilm in chronic wounds to be $78 \%$ [14] and often polymicrobial in composition $[15,16]$. As biofilm is notoriously resilient toward antimicrobial/antibiotic therapy, sharp debridement is the primary removal measure $[17,18]$. However debridement cannot eradicate all traces of the biofilm from the wound and persistent remnants of biofilm can lead to rapid reformation [19, 20]. Therefore, combination of debridement with adjunct antimicrobial therapies provides additional control in managing biofilm via suppression of biofilm reformation $[18,21]$.

Microbial colonization, biofilm, inflammation, wound chronicity and infection are intrinsically linked, and these complications culminate in a high societal and economic impact. Patient quality of life is adversely affected by wound healing complications, pain and malodour $[22,23]$, with wound pain and malodour correlating to infection $[7,23]$. Chronic wounds are generally associated with the lower limbs and extremities, imparting disability such as impaired mobility [24] and significant risk of amputation exists for chronic wounds if healing is unsuccessful [25-27].

Wound dressings with antimicrobial functionality protect the wound dressing from microbial colonization and provide an antimicrobial barrier to the wound. Reducing the risk of microbial colonization additionally minimizes the risk of transmission of pathogenic microbes arising at dressing changes when microbial aerosol release can directly contaminate personnel and environmental surfaces [28, 29]. Silver has been used as an antimicrobial for centuries and in recent decades has risen as a prevalent measure to control microbial challenges in wound and burn management [30]. While various forms of silver such as silver salts (i.e. chloride, nitrate, sulphanilamide) and elemental silver (i.e. silver metal, silver nanoparticles) have been utilized, the antimicrobial properties of silver are due to ionic silver, $\mathrm{Ag}^{+}$ $[31,32]$. Ionic silver functions as a microbiocide by reacting with nucleophilic moieties such as amino, sulfhydryl, and carboxyl groups within proteins and enzymes leading to protein denaturation [33]. Further lethality toward microorganisms is achieved through interference with DNA transcription and respiratory systems [34]. Low concentrations of ionic silver have been shown to collapse the proton motive force across the bacterial membrane, inducing proton leakage and inhibiting cellular respiration [35]. In an age of antimicrobial drug resistance, clinicians are facing more serious infections with less therapeutic options for treatment [36]. In this regard ionic silver provides a microbial control option which does not detract from antimicrobial stewardship practices, with ionic silver formulations acting to prevent microbial colonization and thus reduce incidence of systemic infection and the requirement for systemic or topical antibiotic treatment. Ionic silver itself has negligible resistance potential due to its multi-target mechanism of action [37] and does not demonstrate cross-resistance with antibiotics [38].

While there is prevalent use of antimicrobial silver formulations in wound care, several limitations with current silver technologies exist. Notably, local toxicity of the silver towards fibroblasts and epithelial cells is acknowledged and can manifest as delayed or impaired wound closure [39-41]. Silver cytotoxicity is dose dependent and is due to its non-specific mechanisms of action which are largely indiscriminate between mammalian cells or microorganisms [42]. As cell viability must be maintained to facilitate wound healing the antimicrobial effects of silver must be balanced with the 
potential for cytotoxicity toward mammalian cells. Therefore, it is important for such silver technologies to optimize the therapeutic index, the relationship between antimicrobial activity and the mammalian cell tolerance. Current silver-based wound technologies typically have a narrow therapeutic index, and therefore compromise cytotoxicity towards dermal cells and antimicrobial effectiveness.

In the field of tissue engineering and regeneration, collagen scaffolds may be classified into two categories, materials comprising reconstituted collagen and decellularized extracellular matrices (dECM) [43]. The $\mathrm{dECM}$ biomaterials are produced via manufacturing processes that remove cellular components of the source tissues, leaving an intact and functional scaffold that mimics the ECM of normal tissues [44]. As cellular components of the source tissue are removed during processing, the inflammatory response to $\mathrm{dECM}$ biomaterials is more consistent with constructive remodelling rather than a foreign body immunogenic response [45]. An obvious advantage of dECM biomaterials over reconstituted collagen materials is that dECMs comprise not only collagen but also retain structural, adhesion and signalling molecules found in normal tissues [46]. This complex heterogeneous mixture of molecules better recapitulates the host tissue ECM relative to reconstituted materials and has greater potential for evoking recruitment, adhesion and signalling host cells during the regenerative process relative to denatured/reconstituted collagen based materials alone [47]. We have previously described a $\mathrm{dECM}$ biomaterial prepared from ovine (sheep) forestomach, termed ovine forestomach matrix (OFM). This biomaterial has been shown to contain structural collagens I and III, in addition to secondary ECM components such as remnants of the basement membrane (laminin and collagen IV), glycosaminoglycans, fibronectin and elastin [48]. The matrix present in OFM have been shown to retain the native structure seen in normal tissue [49]. When implanted in vivo and in clinical use the biomaterial provides a platform for cell recruitment, attachment, infiltration and proliferation leading to blood vessel formation and reepithelialisation [48, 50-53].

To our knowledge, little work has been published on the functionalization of $\mathrm{dECM}$ materials with antimicrobial silver. The lack of silver-functionalized AECM dressings is unexpected considering the widespread availability of reconstituted collagen dressings which have been functionalized with silver. Although the biological advantages of $\mathrm{dECM}$ materials relative to reconstituted collagen materials are well established [54-56], the logical progression of functionalizing a dECM with antimicrobial silver has not been pursued. We hypothesized that a $\mathrm{DECM}$ biomaterial could be functionalized with ionic silver to impart antimicrobial effectiveness to the scaffold whilst retaining native ECM structure, composition and function. Given the broad molecular diversity of dECM materials relative to reconstituted collagen, the corresponding binding and release mechanisms of ionic silver to a dECM may impart improved functional properties beneficial for wound healing and tissue regeneration applications.

\section{Materials and methods \\ General}

Ovine forestomach matrix was prepared from ovine forestomach tissue from New Zealand sourced animals < 12 months old (Aroa Biosurgery). Prior to lyophilisation, the decellularized matrix was functionalized with ionic silver according to a proprietary method, whereby the matrix was exposed to dilute solutions of aqueous silver nitrate. Binding of ionic silver to the matrix is achieved via ionic interaction between the cationic silver and anionic matrix protein side chain residues, without cross-linking of silver to the matrix. After exposure to silver nitrate and removal of excess unbound ionic silver, the matrix was freeze-dried, cut to size and terminally sterilized using ethylene oxide to produce OFM-Ag. Ovine Forestomach Tissue (OFT) was prepared according to previously described methods [49]. Commercial antimicrobial dressings collagen/oxidized regenerated cellulose (ORC)-silver (Promogran ${ }^{\circ}$ Prisma, Systagenix) and collagen-silver (Puracol ${ }^{\circ}$ Plus Ag+, Medline), standard cotton gauze dressing (ES-Kompressen Gauze Dressing, Paul Hartmann Ag) and silicone wound care film (Mepitel ${ }^{\circ}, M_{0}$ lnlycke Health Care) were purchased from commercial vendors.

Microbial species were obtained from the New Zealand Reference Culture Collection (Institute of Environmental Science and Research, New Zealand) and were cultured using media and conditions described in Table 1.

Murine 3T3 fibroblasts (ATCC CRL-1658) were cultured in Dulbecco's Minimal Essential Media (DMEM) supplemented with $5 \%$ fetal calf serum (FCS, Invitrogen) (DMEM5) and pen/strep (penicillin $100 \mathrm{U} / \mathrm{mL}$, streptomycin $100 \mu \mathrm{g} / \mathrm{mL}$, Invitrogen). Cell cultures were incubated at $37^{\circ} \mathrm{C}$ at $5 \% \mathrm{CO}_{2} .3 \mathrm{~T} 3$ cells were passaged using $0.25 \%$ trypsin (Invitrogen) at $37^{\circ} \mathrm{C}$ for $5 \mathrm{~min}$.

Statistical significance between groups was determined by 2 -sample t-test unless otherwise stated. Graphical and statistical analysis was performed using Excel 2013 (Microsoft), Sigma Plot 14.0 (Systat Software) and Minitab 17.2.1 (Minitab Inc).

\section{Silver quantification and distribution}

The silver concentration of test samples was determined by standard atomic absorption spectroscopy (AAS) 
Table 1 Microbial Species and Culture Conditions

\begin{tabular}{|c|c|c|c|c|c|}
\hline \multirow[t]{2}{*}{ Species } & \multirow{2}{*}{$\begin{array}{l}\text { ATCC } \\
\#\end{array}$} & \multirow[t]{2}{*}{ Type } & \multicolumn{3}{|c|}{ Culture Conditions } \\
\hline & & & Media & Temp $\left({ }^{\circ} \mathrm{C}\right)$ & Time (hours) \\
\hline Acinetobacter baumannii & 19606 & Gram negative bacterium & TSB & $35 \pm 5$ & $24-48$ \\
\hline Vancomycin Resistant Enterococcus faecalis (VRE) & 51575 & Gram positive bacterium, drug resistant & VRE Broth & $35 \pm 5$ & $24-48$ \\
\hline Escherichia coli & 8739 & Gram negative bacterium & TSB & $35 \pm 5$ & $24-48$ \\
\hline Methicillin Resistant Staphylococcus aureus (MRSA) & 33591 & Gram positive bacterium, drug resistant & TSB & $35 \pm 5$ & $24-48$ \\
\hline Staphylococcus epidermidis (coagulase negative) & 12228 & Gram positive bacterium & TSB & $35 \pm 5$ & $24-48$ \\
\hline Streptococcus pyogenes (Group A, $\beta$-hemolytic) & 12344 & Gram positive bacterium & $\mathrm{BHI}$ & $35 \pm 5$ & $24-48$ \\
\hline Pseudomonas aeruginosa & 27853 & Gram negative bacterium & TSB & $35 \pm 5$ & $24-48$ \\
\hline Aspergillus brasiliensis (niger) ${ }^{a}$ & 16404 & Mold & SDA & $25 \pm 2$ & $48-96$ \\
\hline Candida albicans & 10231 & Yeast & TSB & $25 \pm 2$ & $48-96$ \\
\hline Candida parapsilosis & 22019 & Yeast & SDB & $25 \pm 2$ & $48-96$ \\
\hline Candida glabrata & 90030 & Yeast & SDB & $25 \pm 2$ & $48-96$ \\
\hline
\end{tabular}

Tryptic Soy Broth (TSB), Brain Heart Infusion (BHI). Sabouraud Dextrose Broth/Agar (SDB/A)

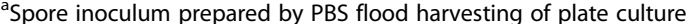

procedures, with modifications [57]. Samples were hydrolyzed in concentrated $\mathrm{HNO}_{3}$ at a ratio of $20 \mathrm{mg}$ sample per $\mathrm{mL}$, with incubation for $16 \mathrm{~h}$ at room temperature followed by $80^{\circ} \mathrm{C}$ for $2 \mathrm{~h}$. Samples were diluted in $2 \%$ aqueous $\mathrm{HNO}_{3}$ prior to air-acetylene flame AAS using an XplorAA (GBC Scientific Equipment Pty Ltd) and Ag hollow cathode lamp. Silver concentration of samples was determined relative to a standard curve of certified reference material (TraceCERT Silver Standard for AAS, Sigma-Aldrich) prepared in $2 \%$ aqueous $\mathrm{HNO}_{3}$. Silver concentration was expressed as $\% \mathrm{w} / \mathrm{w}$ based on the initial mass of the sample, digest volume and dilution.

Distribution of silver in samples was assessed via scanning electron microscopy (SEM) and light microscopy of silver visualized samples. For SEM, $2 \times 5 \mathrm{~mm}$ samples were mounted to aluminium stubs (Amray 1000 specimen mount) and imaged using a Hitachi TM3030 scanning electron microscope (University of Auckland, New Zealand) at an accelerating voltage of $15 \mathrm{kV}$.

For light microscopy, $10 \times 10 \mathrm{~mm}$ samples were incubated for $1 \mathrm{~h}$ in $2 \mathrm{~mL}$ silver stain developer solution (Pierce Silver Stain Kit, Thermo Fisher) at room temperature with 10 RPM shaking to visualize ionic silver content via reduction. Samples were then fixed in $10 \%$ neutral buffered formalin (Sigma Aldrich) for $24 \mathrm{~h}$ and histology samples prepared by ethanol gradient dehydration, paraffin embedding, $10 \mu \mathrm{m}$ sectioning and mounting to slides. Slides were deparaffinized, hydrated, stained with hematoxylin and eosin (H\&E) per manufacturer's instructions (Sigma-Aldrich). Slides were imaged via 100x objective under oil immersion using a Leica DMR upright microscope and Nikon Digital Sight Camera (University of Auckland, New Zealand) using Nikon NIS Elements image acquisition software.

\section{Collagen quantification}

The total collagen concentration of OFM and OFM-Ag samples was determined via hydroxyproline analysis according to established procedures [58] using a commercial assay kit (Hydroxyproline Assay Kit, Chondrex Inc). Briefly, test samples $(50 \mathrm{mg}$ ) and positive controls (collagen I, rat tail, Sigma) were subject to acid hydrolysis in $1 \mathrm{~mL} 6 \mathrm{M} \mathrm{HCl}$ at $120^{\circ} \mathrm{C}$ for $16 \mathrm{~h}$. Hydrolyzed samples were centrifuged at 10,000 RPM for $3 \mathrm{~min}$ and supernatant diluted with reverse osmosis purified water $\left(\mathrm{ROH}_{2} \mathrm{O}\right)$ 1:80 into fresh tubes. Diluted samples and hydroxyproline standards $(10 \mu \mathrm{L})$ were added to 96 well plate in duplicate. Chloramine T solution in neutralizing buffer $(100 \mu \mathrm{L})$ was added and incubated for $20 \mathrm{~min}$ at room temperature after which 4-(dimethylamino)benzaldehyde (DMAB) solution $(100 \mu \mathrm{L})$ was added and incubated at $60^{\circ} \mathrm{C}$ for $30 \mathrm{~min}$. Absorbance was measured at $550 \mathrm{~nm}$ using a FluoStar Omega plate reader (BMG Labtech) and sample hydroxyproline concentration determined by linear regression. Total collagen was calculated by multiplication of hydroxyproline concentration by $100 / 13.5$ and expressed as $\mathrm{mg} / \mathrm{g}$ based on initial sample mass and hydrolysis volume [59].

\section{Glycosaminoglycan quantification}

Glycosaminoglycan (GAG) concentration of OFM and OFM-Ag was determined via total sulphated GAG assay according to established procedures [60] utilizing a commercial assay kit (Blyscan Sulfated Glycosaminoglycan Assay Kit, Biocolor). Briefly, test samples $(50 \mathrm{mg})$ were digested in $1 \mathrm{~mL}$ of $0.5 \mathrm{mg} / \mathrm{mL}$ papain (Sigma) solution for $16 \mathrm{~h}$ at $65^{\circ} \mathrm{C}$. Digests were centrifuged at 13,000 RPM for $10 \mathrm{~min}$ and $350 \mu \mathrm{L}$ supernatant added to $1400 \mu \mathrm{L}$ absolute ethanol in a fresh tube and stored at $20{ }^{\circ} \mathrm{C}$ for $2 \mathrm{~h}$ to precipitate GAGs followed by 
centrifugation at 13,000 RPM for $10 \mathrm{~min}$. Supernatant was removed and the pellet resuspended in $350 \mu \mathrm{L}$ $\mathrm{ROH}_{2} \mathrm{O}$ via vortex. Samples were diluted 1:10 in $\mathrm{ROH}_{2} \mathrm{O}$ to a volume of $100 \mu \mathrm{L}$ in fresh tubes. Standard curve and positive control samples were prepared from dilutions of chondroitin sulphate in $\mathrm{ROH}_{2} \mathrm{O}$ and $750 \mu \mathrm{L}$ of dye reagent (1,9-dimethylmethylene blue) added to test samples, controls and standards followed by agitated incubation for $30 \mathrm{~min}$ and centrifugation at 13,000 RPM for $30 \mathrm{~min}$. Supernatant was removed and pellets resuspended in $600 \mu \mathrm{L}$ dissociation buffer. Test samples, controls and standards $(250 \mu \mathrm{L})$ were transferred to a 96 well plate and $630 \mathrm{~nm}$ absorbance measured using a FluoStar Omega plate reader (BMG Labtech). GAG concentration was determined by linear regression and expressed as $\mathrm{mg} / \mathrm{g}$ based on initial sample mass and digestion volume.

\section{Onset melt temperature}

Test materials were hydrated in phosphate buffered saline (PBS) ( $\mathrm{pH} 7.4)$ and sample mass of $5-20 \mathrm{mg}$ cut by biopsy punch. Samples were placed flat in aluminum Tzero Analysis pans (TA Instruments) and lids hermetically sealed. Calorimetric measurement used a nitrogen purged Q20 DSC (TA Instruments) with parameters of $10^{\circ} \mathrm{C}$ equilibration and ramp of $8{ }^{\circ} \mathrm{C} / \mathrm{min}$ to $120^{\circ} \mathrm{C}$. Onset melt temperature $\left(\mathrm{T}_{\mathrm{m}}\right)$ was determined by sigmoidal baseline integration using TA Universal Analysis v4.5A software.

\section{Silver elution profile}

OFM-Ag samples measuring $5.08 \times 5.08 \mathrm{~cm}$ were eluted via immersion in $\mathrm{ROH}_{2} \mathrm{O}(7.5 \mathrm{~mL})$ and incubated at $37^{\circ}$ $\mathrm{C}$ for a time course of up to 7 days. Every $24 \mathrm{~h} \mathrm{ROH}_{2} \mathrm{O}$ elution medium was removed and replaced. At assay time points of 1,3 and 7 days, eluted samples were removed and lyophilized to obtain a dry mass. The silver content of lyophilized samples was quantified via AAS as previously described to determine the amount of silver remaining over the elution time course. Results were expressed as \% initial silver remaining over time based on pre-elution silver content.

\section{Antimicrobial effectiveness}

Antimicrobial effectiveness testing utilized the method described in ISO 20743:2007. Briefly, microbial inoculum was prepared from cryostock using culture conditions specified in Table 1.

Test and non-antimicrobial control samples $(5.08 \times$ $5.08 \mathrm{~cm}$ ) were placed flat in a sterile petri dishes and preconditioned by hydration in simulated wound fluid (SWF, 50\% bovine serum and 50\% microbiological media) for $5 \mathrm{~min}$ at $37^{\circ} \mathrm{C}$ prior to inoculation. Preconditioned samples were inoculated with $100 \mu \mathrm{L}$ microbial challenge ( $>10^{6}$ Colony Forming Units, CFU), sealed to maintain humid environment and incubated at $37^{\circ} \mathrm{C}$ for the assay time period (1, 3 or 7 days), for time zero samples $\left(\right.$ Control $_{t=0}$ and Treatment $t_{t=0}$ ) inoculation occurred immediately prior to neutralization. After the assay time period, residual antimicrobial activity of samples was neutralized via immersion in $100 \mathrm{~mL}$ of sterile neutralizing buffer (thiosulfate containing PBS, per Difco Microbiology Manual) and microorganisms extracted via stomacher for $5 \mathrm{~min}$. Neutralized extracts were serial diluted in sterile PBS and $0.45 \mu \mathrm{m}$ membrane filtration plated to solid media for enumeration via the culture conditions of Table 1. Controls (PBS and SWF sterility, inoculum titre of $>10^{6} \mathrm{CFU} /$ sample) were included in all assays. After enumeration incubation, colonies were quantified and expressed as $\log _{10} \mathrm{CFU} /$ sample. Antimicrobial effectiveness, expressed as log reduction, was determined from the mean of the triplicate test samples for each microbial species at each assay time point based on the equation defined in ISO 20743:2007;

$$
\begin{aligned}
\log \text { Reduction } & =\left(\log \text { Control }_{t=24}-\text { Log }_{\text {Control }} t=0\right) \\
& -\left(\log \text { Treatment }_{t=x}-\text { Log }_{\text {Treatment }} \text { Tr=0 }\right)
\end{aligned}
$$

Where ' $\mathrm{t}=\mathrm{x}$ ' is the time point under consideration ( $\mathrm{t}$ $=1$ day, 3 day or 7 day).

\section{Minimum effective concentration}

OFM-Ag material was prepared with target silver concentrations of $\sim 0.10 \%, \sim 0.15 \%, \sim 0.20 \%$ and $\sim 0.30 \% \mathrm{w} /$ w. Silver concentration of samples was determined by AAS prior to antimicrobial effectiveness determination. Samples were assessed for antimicrobial effectiveness over a one day assay time course utilizing $S$. epidermidis, $P$. aeruginosa, and C. glabrata as representative species of gram positive, gram negative and yeast, respectively.

\section{Biofilm prevention assay}

Biofilm prevention of OFM-Ag, standard cotton gauze (ES-Kompressen) and commercial antimicrobial wound dressings collagen/ORC-silver and collagen-silver was assessed using an established microtiter plate crystal violet assay [61], with modifications. Cultures of $P$. aeruginosa, S. epidermidis and C. glabrata were prepared in TSB from agar plate stocks with 150 RPM incubation at $37^{\circ} \mathrm{C}$ for $16 \mathrm{~h}$ for bacteria and $25^{\circ} \mathrm{C}$ for $24 \mathrm{~h}$ for yeast. Polymicrobial inoculum was prepared by combining $P$. aeruginosa, S. epidermidis and C. glabrata cultures at a volume ratio of 1:1:8 and the concentration of each species in the inoculum quantified by serial dilution, spiral plating and incubation according to the conditions of Table 1. To tissue-culture coated 12 -well plates, $800 \mu \mathrm{L}$ of SWF was added to each well followed by $200 \mu \mathrm{L}$ of the polymicrobial inoculum, with the exception of 
control wells which received $800 \mu \mathrm{L}$ of SWF and $200 \mu \mathrm{L}$ of TSB. Plates were statically incubated for $2 \mathrm{~h}$ at $33^{\circ} \mathrm{C}$ (representing dermal wound temperature [62]) for microbial attachment, after which medium was removed via pipette and wells rinsed twice with PBS $(4 \mathrm{~mL})$ to remove non-adhered microbes. Initial biofilm was also quantified at this point for reference. Test samples were cut to $20 \mathrm{~mm}$ diameter discs via biopsy punch and overlaid with a layer of semi-occlusive silicone dressing $\left(M^{2}\right.$ itel $\left.{ }^{\circ}\right)$. Samples were pre-hydrated to saturation with TSB for $15 \mathrm{~min}$, excess TSB was removed and samples applied to wells with the test sample contacting the well biofilm surface. Plates were covered with aluminium seals and statically incubated at $33^{\circ} \mathrm{C}$ for $24 \mathrm{~h}$, after which test samples were removed, wells gently rinsed twice with PBS $(4 \mathrm{~mL})$ to remove non-adhered microbes and plates dried under laminar flow. Crystal Violet (1 $\mathrm{mL}, 0.5 \%$ in $\mathrm{ROH}_{2} \mathrm{O}$ ) was added to wells, incubated at room temperature for $15 \mathrm{~min}$ and removed by pipette. Plates were rinsed three times by submersion in water to remove unbound stain followed by drying under laminar flow. Bound Crystal Violet was solubilized by adding 1 $\mathrm{mL}$ of acetic acid $\left(30 \% v / \mathrm{v}\right.$ in $\left.\mathrm{ROH}_{2} \mathrm{O}\right)$ and mixing at 50 RPM for $15 \mathrm{~min}$ at room temperature. Solubilized samples were diluted 1:10 in acetic acid $(30 \% \mathrm{v} / \mathrm{v}$ in $\mathrm{ROH}_{2} \mathrm{O}$ ), $200 \mu \mathrm{L}$ transferred to 96-well plates and absorbance at $570 \mathrm{~nm}$ measured using a FluoStar Omega (BMG Labtech). Values of the blank (non-inoculated) sample controls were subtracted from corresponding test samples to account for any interference from the test samples. Pairwise multiple comparison (Tukey's test) was used to assess differences in group means.

\section{Cytotoxicity - MEM elution and ionic silver dose response curve}

Test samples were extracted per ISO10993-12, whereby samples were rehydrated in sterile saline for $5 \mathrm{~min}$ to account for absorbency then extracted in DMEM at a ratio of $6 \mathrm{~cm}^{2}$ (double sided) per $1 \mathrm{~mL}$ DMEM with incubation at $37^{\circ} \mathrm{C}$ and $100 \mathrm{RPM}$ for $24 \mathrm{~h}$. Samples of ionic silver were prepared by dissolving $\mathrm{AgNO}_{3}$ in $\mathrm{ROH}_{2} \mathrm{O}$ and diluting in DMEM to $32 \mu \mathrm{g} / \mathrm{mL} \mathrm{Ag}^{+}$. The stock solution was serially diluted 1:1 in DMEM to give a concentration series, 0 to $32 \mu \mathrm{g} / \mathrm{mL} \mathrm{Ag}^{+}$. FBS (5\% final concentration) was added to all test samples. NIH/3 T3 murine fibroblasts were grown to $70-80 \%$ confluency, trypsinized $(0.25 \%$ for $5 \mathrm{~min})$, diluted and $100 \mu \mathrm{L}$ plated to 96-well tissue culture $(40,000$ cells/well) and incubated for $24 \mathrm{~h}$ until $70-80 \%$ confluent. Media was aspirated and test samples $(100 \mu \mathrm{L})$ added to the monolayers. Cells were incubated for $24 \mathrm{~h}$ at which time cell viability was quantified via (3-(4,5-dimethylthiazo1-2-yl)-2,5-diphenyltetrazolium bromide) MTT assay according to established procedures described in ISO10993-5. Cell viability was expressed as a percentage of media only (DMEM5) control. The 50\% inhibitory concentration $\left(\mathrm{IC}_{50}\right)$ value for ionic silver was calculated using Sigma Plot four parameter logistic curve non-linear regression.

\section{Results}

\section{Material characterization}

Relative to OFM, silver functionalization of OFM-Ag at a nominal concentration of $0.30 \% \mathrm{w} / \mathrm{w}$, demonstrated negligible effects toward the primary and secondary composition as determined by total collagen and GAG concentration (Table 2).

Inclusion of ionic silver in OFM-Ag did not substantially alter the total collagen concentration relative to non-silver containing OFM. The GAG concentration of OFM-Ag was also not significantly reduced relative to OFM $(p>0.05)$ indicating the additional processing required for silver functionalization was not detrimental to highly soluble ECM secondary components such as GAGs. Onset melt temperature $\left(\mathrm{T}_{\mathrm{m}}\right)$, an indicative measure of the native structural integrity of the ECM, showed OFM-Ag retained the preserved native ECM structure similar to non-silver functionalized OFM material, both in quantitatively determined $\mathrm{T}_{\mathrm{m}}$ (Table 2 ) and thermogram profile (Fig. 1).

Thermograms for OFM and OFM-Ag closely resemble that of the unprocessed source tissue, OFT, with only a minor shift of the melt transition. The difference in $T_{m}$ between the unprocessed OFT and the processed OFM and OFM-Ag was slight, but statistically significant $(p<0.05)$ and expected from the processing required to

Table 2 Material Characterization

\begin{tabular}{|c|c|c|c|c|c|}
\hline & Collagen/ORC-silver & Collagen-silver & OFT & OFM & OFM-Ag \\
\hline Silver (\%w/w) & 0.25 & $0.9^{\mathrm{a}}$ & N/A & $\mathrm{N} / \mathrm{A}$ & $0.30 \pm 0.03$ \\
\hline Total Collagen (\%w/w) & 55 & 100 & N/A & $88.96 \pm 2.95$ & $85.48 \pm 5.07$ \\
\hline Total GAGs (mg/g) & None & None & N/A & $4.13 \pm 0.30$ & $4.60 \pm 0.62$ \\
\hline $\mathrm{T}_{\mathrm{m}}\left({ }^{\circ} \mathrm{C}\right)$ & $29.62 \pm 3.89$ & $49.13 \pm 1.53$ & $65.45 \pm 0.74$ & $61.60 \pm 0.57$ & $60.78 \pm 1.63$ \\
\hline
\end{tabular}

Values represent mean \pm standard deviation of $n=133$ samples (silver) and $n=19$ samples (collagen, GAGs and $T_{m}$ )

Silver and collagen total collagen of collagen/ORC-silver and collagen-silver dressings derived from manufacturer's product information. Data for OFT and OFM derived from Sizeland et al [49]

${ }^{\mathrm{a}}$ Manufacturer label states $1.2 \% \mathrm{AgCl}$, equating to $0.9 \% \mathrm{Ag}$ 


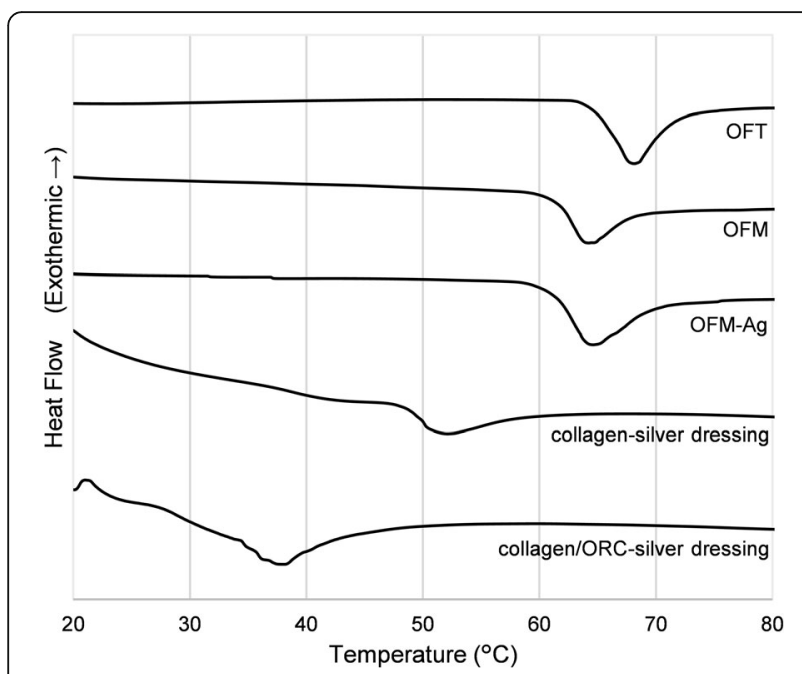

Fig. 1 Differential Scanning Calorimetry (DSC) Thermograms. Representative thermograms derived from the mean of triplicate samples. Y-axis is arbitrarily offset to allow simultaneous plotting of all thermograms

decellularize and sterilize a raw material to produce a dECM. However, there was no significant difference in $T_{m}$ between OFM and OFM-Ag $(p>0.05)$, indicating additional processing steps required for silver functionalization of the matrix did not impact the native ECM structure.

In contrast, thermograms for both collagen-silver and collagen/ORC-silver dressings were shallow during the melt transition event, with little heat flux or step-change in pre/ post melt heat capacity (Fig. 1). Both commercial dressings had significantly lower $\mathrm{T}_{\mathrm{m}}$ compared to OFM-Ag $(p<0.001)$, with the $\mathrm{T}_{\mathrm{m}}$ of the collagen-silver dressing indicating some loss of native collagen structure but not complete denaturation, whereas the collagen/ORC-silver dressing exhibited a $T_{m}$ below physiological temperature, indicative of extensive denaturation to the collagen structure.

Under SEM, OFM-Ag (Fig. 2a) appeared identical to the non-silver functionalized OFM (Fig. 2b), indicating the silver content of OFM-Ag to be bound to the matrix in ionic form. After treatment with a reducing agent the silver content of OFM-Ag was readily observable under light microscopy as an even distribution of silver associated matrix collagen fibres (Fig. 2c). As expected, the non-silver functionalized OFM control exhibited no discernible silver after reducing agent treatment (Fig. 2d).

\section{Elution kinetics}

Elution of ionic silver from OFM-Ag material was measured over a time course of simulated use in aqueous medium to determine the proportion of silver remaining in the biomaterial over a seven day duration (Fig. 3). Elution kinetics of ionic silver from OFM-Ag $(0.30 \% w /$ w silver), demonstrated $<10 \%$ loss within the first $24 \mathrm{~h}$, increasing to a $\sim 40 \%$ loss after 3 days of elution. There

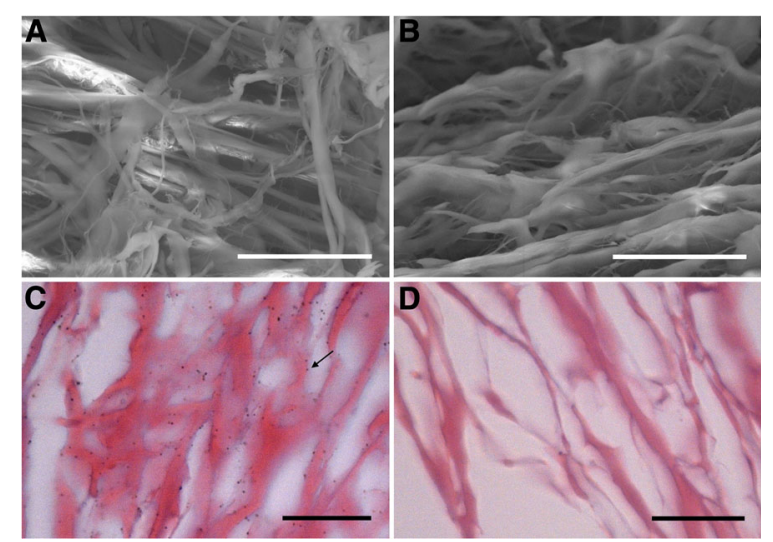

Fig. 2 Distribution of Silver in OFM-Ag. (a) SEM of OFM-Ag, scale bar $30 \mu \mathrm{m}$. (b) SEM of OFM, scale bar $30 \mu \mathrm{m}$. (c) Light microscopy of silver-visualized OFM-Ag, arrow indicates silver particle formed by silver-visualization processing, scale bar $25 \mu \mathrm{m}$. (d) Light microscopy of silver-visualized OFM, scale bar $25 \mu \mathrm{m}$

was no appreciable further loss of ionic silver following seven days of elution, with samples retaining approximately $60 \%$ of the initial ionic silver.

\section{OFM-ag minimum effective antimicrobial concentration}

OFM-Ag with ionic silver concentrations over the range, $0.08 \pm 0.01 \% \mathrm{w} / \mathrm{w}$ to $0.28 \pm 0.02 \% \mathrm{w} / \mathrm{w}$ were screened against S. epidermidis, P. aeruginosa, and C. glabrata as representative species of gram positive, gram negative and fungal microorganisms, in order to determine the Minimum Effective Concentration (MEC).

OFM-Ag at concentrations of $0.15 \pm 0.02 \% w / w$ to 0.28 $\pm 0.02 \% \mathrm{w} / \mathrm{w}$ demonstrated antimicrobial effectiveness ( $>4 \log$ reduction) toward all microbial types (Fig. 4). Effectiveness of OFM-Ag at $0.08+/-0.01 \% \mathrm{w} / \mathrm{w}$ toward $C$. glabrata was variable, with test replicates below a 4 log reduction (Fig. 4). Additionally, although the $0.08 \pm 0.01 \%$

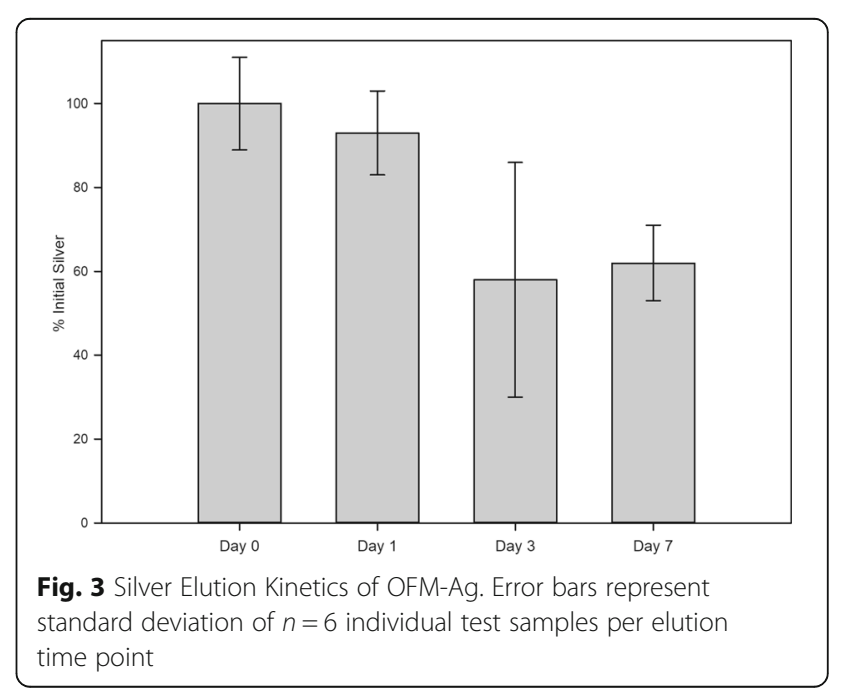




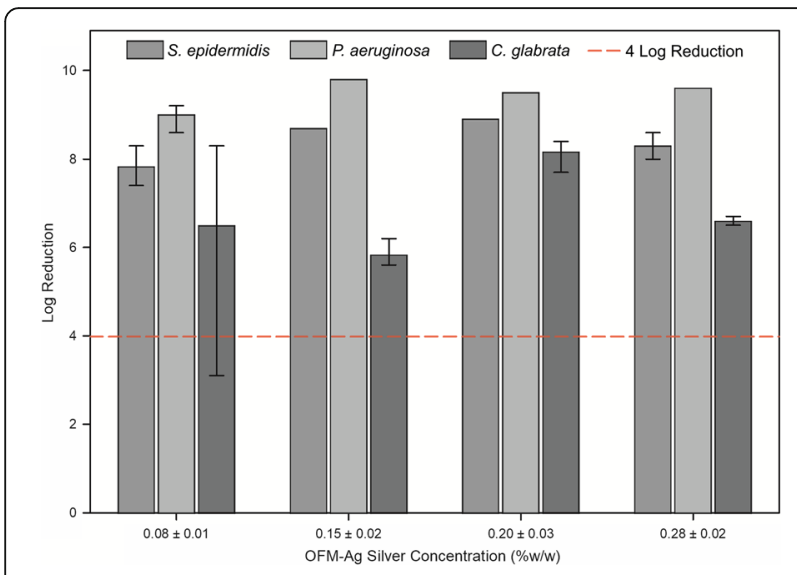

Fig. 4 OFM-Ag Minimum Effective Antimicrobial Concentration. Log reduction against $S$. epidermidis, $P$. aeruginosa and C. glabrata. Data represents mean of triplicate test samples per species, per concentration. Error bars indicate minimum and maximum log reduction, data points without error bars indicate no variation in triplicate data. Reference line indicates $4 \log$ reduction. $\mathrm{X}$-axis silver concentrations are mean \pm standard deviation of $n=19$ samples

$w / w$ silver concentration achieved good log reduction values toward $S$. epidermidis and $P$. aeruginosa, this did not result in a complete kill of these organisms in all sample replicates. Considering this, the MEC of ionic silver in OFM-Ag was conservatively determined to be $0.15 \% \mathrm{w} / \mathrm{w}$ in order provide consistent antimicrobial effectiveness $(>4 \log$ reduction) toward gram positive, gram negative and fungal microorganisms.

\section{Antimicrobial effectiveness spectrum and wear time}

Antimicrobial effectiveness of OFM-Ag prepared at a nominal silver concentration $(0.30 \% \mathrm{w} / \mathrm{w})$ was determined toward a spectrum of microbial species. The mean silver concentration of samples tested for antimicrobial effectiveness spectrum and wear time was determined by AAS to be $0.30 \pm 0.03 \% w / \mathrm{w}$, or $12 \pm 1 \mu \mathrm{g} / \mathrm{cm}^{2}$.

OFM-Ag at a nominal silver concentration of $0.30 \pm$ $0.03 \% \mathrm{w} / \mathrm{w}$ exhibited broad spectrum antimicrobial effectiveness against both gram positive and gram negative organisms and a selection of yeast and mold (Table 3). OFM-Ag was protected from microbial challenge throughout a 7 day wear time, with $>6 \log$ reduction against all organisms across all time points. One exception was the effectiveness against the mold species $A$. brasiliensis where at the 1 day time point, OFM-Ag achieved only a mean $\log$ reduction of 1.8 . However, at the later day 3 and 7 time points, OFM-Ag effectiveness against $A$. brasiliensis increased to a log reduction of $>5.3$.

\section{Biofilm formation}

In the in vitro biofilm prevention assay OFM-Ag $(0.30 \pm$ $0.03 \% \mathrm{w} / \mathrm{w}$ ) was the most effective test sample followed by collagen/ORC-silver, collagen-silver. As expected, the negative control, gauze, was ineffective (Fig. 5). Pairwise comparison showed OFM-Ag resulted in significantly lower biofilm formation compared to all other dressings tested $(p<0.05)$. The collagen/ORC-silver test sample was also significantly lower than collagen-silver $(p<0.05)$. Although at face value collagen-silver exhibited greater biofilm prevention than the negative control, gauze, this result was not significant $(p>0.05)$.

\section{Cytotoxicity}

The cytotoxicity dose response of ionic silver toward mammalian fibroblasts determined by MTT assay is shown in Fig. 6a. The cytotoxicity dose-response of $\mathrm{Ag}^{+}$was a typical sigmoidal curve, with an $\mathrm{IC}_{50}$ value of $0.77 \pm 0.06 \mu \mathrm{g} / \mathrm{mL}$ and a maximum non-cytotoxic concentration of $0.50 \mu \mathrm{g} / \mathrm{mL} \mathrm{Ag}^{+}$, per ISO 10993-5 definition of the highest concentration

Table 3 OFM-Ag Antimicrobial Effectiveness Spectrum and Wear Time Data

\begin{tabular}{|c|c|c|c|c|}
\hline \multirow[t]{2}{*}{ Microbial Type } & \multirow[t]{2}{*}{ Species } & \multicolumn{3}{|c|}{ Log Reduction Value } \\
\hline & & 1 Day & 3 Days & 7 Days \\
\hline \multirow[t]{4}{*}{ Gram positive } & Methicillin Resistant Staphylococcus aureus (MRSA) & 7.0 & $>8.5$ & 7.8 \\
\hline & Staphylococcus epidermidis (coagulase negative) & 8.3 & $>8.6$ & $>8.6$ \\
\hline & Streptococcus pyogenes (Group A, $\beta$-hemolytic) & $>7.6$ & $>7.6$ & $>7.6$ \\
\hline & Vancomycin Resistant Enterococcus faecalis (VRE) & 7.5 & 7.8 & $>8.2$ \\
\hline \multirow[t]{3}{*}{ Gram negative } & Acinetobacter baumannii & $>8.6$ & $>8.6$ & $>8.6$ \\
\hline & Escherichia coli & $>6.9$ & $>6.9$ & $>6.9$ \\
\hline & Pseudomonas aeruginosa & $>9.6$ & $>9.6$ & $>9.6$ \\
\hline \multirow[t]{4}{*}{ Fungi } & Candida albicans & 6.1 & $>8.9$ & $>8.9$ \\
\hline & Candida parapsilosis & 7.3 & $>7.6$ & $>7.6$ \\
\hline & Candida glabrata & 6.6 & $>8.5$ & $>8.5$ \\
\hline & Aspergillus brasiliensis (niger) & 1.8 & $>5.3$ & $>5.3$ \\
\hline
\end{tabular}

Values represent mean log reduction of triplicate samples. Prefix ' $>$ ' indicates no microorganisms were recovered at the assay time period, demonstrating a complete kill of the microbial challenge, for calculation these were considered to be $1 \mathrm{CFU}$, the enumeration limit of detection of the undiluted extract 


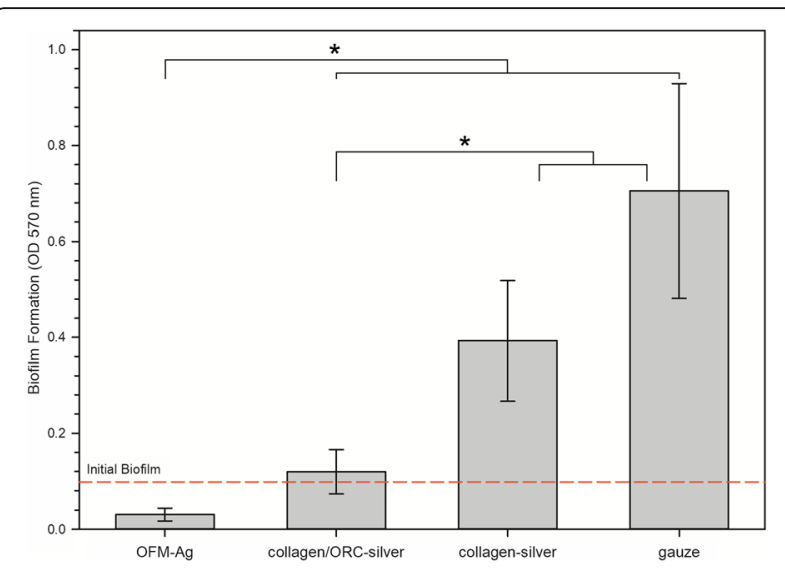

Fig. 5 Biofilm Prevention of OFM-Ag and Commercial Wound Dressings. Error bars represent standard deviation of $n=18$ replicates. Reference line indicates amount of initial naïve biofilm present prior to application of test samples. ${ }^{*}$ indicates statistical difference between groups ( $p<0.05$ via Tukey's pairwise multiple comparison)
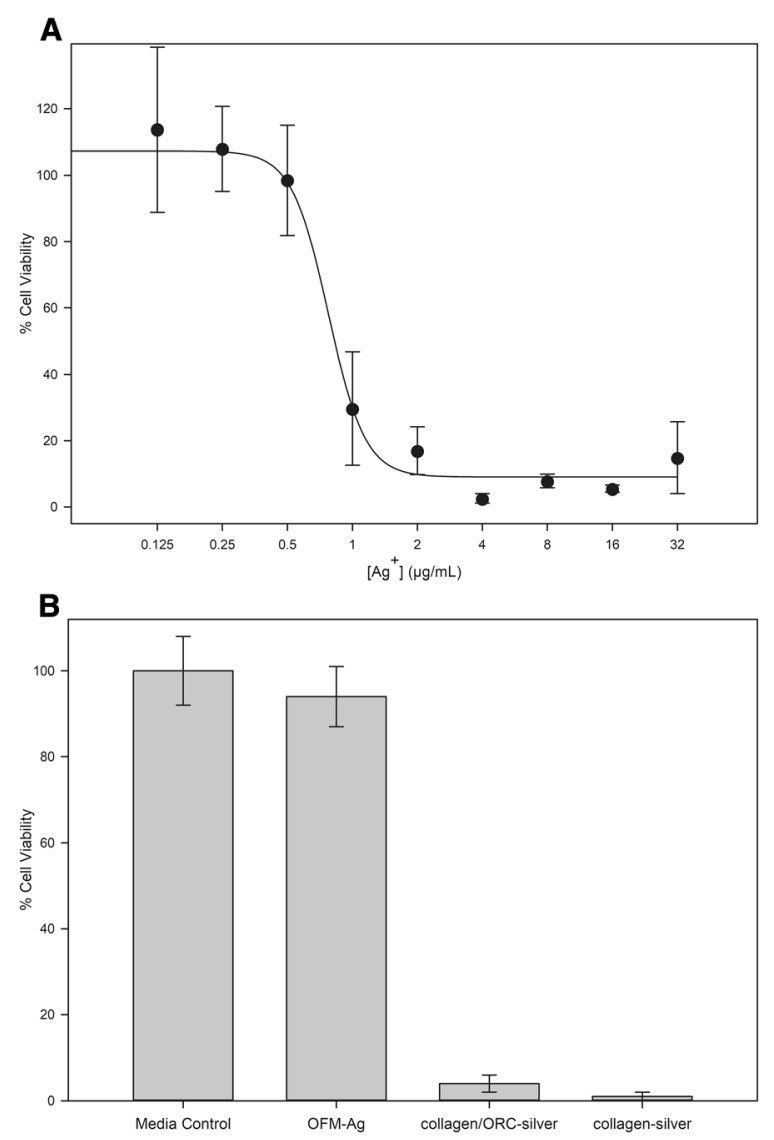

Fig. 6 Cytotoxicity profile of ionic silver, silver-collagen dressings and OFM-Ag. (a) Cytotoxicity dose-response of ionic silver, error bars represent standard deviation of $n=9$ replicates across $n=3$ separate experiments. (b) Cytotoxicity of OFM-Ag and commercial wound dressings. Error bars represent standard deviation of $n=18$ replicates across $n=3$ separate experiments eliciting $>70 \%$ cell viability. This result indicates $\mathrm{Ag}^{+}$alone to be readily cytotoxic toward mammalian fibroblasts.

To benchmark the cytotoxicity profile of OFM-Ag against commercial silver containing collagen dressings, OFM-Ag at the nominal silver concentration of $0.30 \pm$ $0.03 \%(w / w)$, collagen/ORC-silver dressing (ionic silver $0.25 \% \mathrm{w} / \mathrm{w})$ and collagen-silver dressing $(\mathrm{AgCl} 1.2 \% \mathrm{w} /$ w) were assayed.

Both commercial dressings, collagen/ORC-silver and collagen-silver, exhibited a cytotoxic response with markedly decreased cell viability (Fig. 6b). In contrast, OFM-Ag demonstrated no cytotoxicity (Fig. 6b) with cell viability not significantly different to the media only control $(p>0.05)$. Interestingly, despite having a lower silver concentration relative to OFM-Ag, the collagen/ ORC-silver dressing (ionic silver $0.25 \% \mathrm{w} / \mathrm{w}$ ) imparted a significant reduction in cell viability relative to both the media only control $(p<0.001)$ and OFM-Ag $(p<0.001)$. The high silver concentration collagen-silver dressing $(\mathrm{AgCl} 1.2 \% \mathrm{w} / \mathrm{w})$ exhibited a similar cytotoxic response, with significantly lower cell viability as compared to both the media control $(p<0.001)$ and OFM-Ag $(p<0.001)$.

\section{Discussion}

\section{Material characterization}

Due to the complex makeup of $\mathrm{DECM}$ materials and even greater complexity of in vivo interactions, the exact compositional and structural properties for biological utility of dECM scaffold materials in wound healing and tissue regeneration applications have not been defined. To overcome this dECM materials utilize design via a subtraction approach to remove known undesirable components (i.e. cell debris, nucleic acids) from a suitable source material while preserving the native compositional and structural properties of tissue ECM [63]. This approach seeks to aims to generate a close mimic of tissue ECM, providing a biocompatible and ready to populate bioscaffold [64]. The biological functionality of dECMs relative to reconstituted collagen materials has been demonstrated for OFM in terms of protease modulation [65], cell migration, cell proliferation and angiogenesis [50].

Functionalization of OFM with ionic silver involves additional processing steps which could potentially impact the composition and structure of the functionalized $\mathrm{dECM}$. To determine the effects of silver incorporation toward the composition of OFM-Ag, total collagen and total GAGs were assessed to represent insoluble primary ECM and soluble secondary ECM components, respectively. GAGs are an important ECM secondary component which have demonstrated involvement in a vast array of physiological process [66] and contribute to healing via multiple mechanisms [67]. While the primary constituent of the ECM, collagen, is relatively insoluble 
and stable, providing no harsh conditions are used during processing (i.e. enzymatic, high temperature, strong acid or alkali steps) [68], GAGs are highly soluble and labile ECM components [68] rendering them sensitive to removal or degradation by processing conditions $[69,70]$. Thus, GAGs may serve as a useful surrogate marker for retention of similarly soluble and labile secondary molecules in $\mathrm{dECM}$ materials. The commercial product decellularized fetal bovine dermis with ionic silver (Primatrix Ag, TEI Biosciences, Integra) is reported to be devoid of non-collagenous ECM components such as GAGs $[46,71,72]$ suggesting such secondary molecules have been lost in this material. In contrast, equivalence in GAG concentration between OFM and OFM-Ag (Table 2) validates that additional processing required for silver functionalization does not remove soluble ECM secondary molecules from OFM-Ag.

The matrix structure of $\mathrm{dECM}$ biomaterials is integral not only to physical and mechanical properties, but also the resultant cell behaviour and interactions [73]. The biocompatibility and regenerative potential of dECM scaffolds can be adversely affected by process induced damage or modification to the matrix structure [74]. Structural integrity of scaffold biomaterials may be quantitatively assessed using onset melt temperature $\left(\mathrm{T}_{\mathrm{m}}\right)$, determined via a materials thermal stability [75]. For example, degradation of the matrix structure (i.e. protein denaturation, depolymerisation or hydrolysis) reflected in a reduced thermal stability. Conversely, chemically cross-linking increases a materials thermal stability and resultant $\mathrm{T}_{\mathrm{m}}$ [76]. Interestingly, the thermal stability of OFT (Fig. 1 and Table 2) is comparable to that described for normal human dermal tissue [77, 78], such that the $T_{m}$ for OFT not only serves as an indicative benchmark of tissue ECM prior to processing, but also approximates the matrix integrity of healthy human skin.

The results for OFM, collagen/ORC-silver and collagen-silver (Table 2) are in good agreement with published $T_{m}$ determined for these materials [79]. Of interest is the equivalence in thermal stability between OFM and OFM-Ag (Fig. 1 and Table 2), demonstrating silver functionalization did not induce damage or modification to the collagen matrix [64]. The preserved ECM structure of OFM-Ag is in contrast to the thermal stability of collagen/ORC-silver (Fig. 1 and Table 2), which was characteristic of a denatured collagen comprising randomly fragmented fibrils devoid of superstructure (i.e. gelatin) [80]. The thermal stability of collagen-silver dressing presented as an intermediate between denatured collagen and native ECM structure (Fig. 1 and Table 2). This may reflect the retention of the triple helix structure of tropocollagen but not the native cross linkage of collagen fibres characteristic of tissue ECM.
As the silver content of OFM-Ag is presented in ionic form no discernible silver was visible under SEM imaging, with OFM-Ag exhibiting identical appearance to non-silver functionalized OFM characterized by an open porous structure of heterogeneous collagen fibres (Fig. 2a and b). Treatment of samples with a reducing agent elucidated the silver content of OFM-Ag via reduction of ionic silver in OFM-Ag to elemental silver observable under light microscopy. This revealed abundant sub-micron silver particles associated with collagen fibres, evenly distributed throughout the OFM-Ag material (Fig. 2c), whereas the reducing agent treated OFM control showed the same matrix collagen fibre structure with no silver particles (Fig. 2d). Due to the nature of $\mathrm{Ag}^{+}$reduction to elemental silver particles, which grow via nucleation from discrete foci, this method of silver visualization does not provide a true resolution of the expected highly uniform distribution of ionic silver within the individual collagen fibres of OFM-Ag. However, this visualization method demonstrates the overall uniformity of silver distribution throughout the OFM-Ag material.

\section{OFM-Ag silver elution profile}

Characterizing the elution of the antimicrobial agent from material over time provided insights into the anticipated longevity of antimicrobial effectiveness in situ. Previous studies have demonstrated that water is most efficacious at solubilizing ionic silver from silver-containing wound dressings [81]. As such, release kinetics of OFM-Ag utilized purified water to simulate 'worst-case' clinical use. Silver release is also dependant on the volume of wound exudate, which is highly variable between wound type, anatomical location and patient differences,with exudate volumes of $0.10-0.21 \mathrm{~mL} / \mathrm{cm}^{2} /$ day have been reported [82]. As such, a conservatively high elution volume of $0.29 \mathrm{~mL} / \mathrm{cm}^{2} /$ day $(7.5 \mathrm{~mL} /$ day for a $5.08 \times 5.08 \mathrm{~cm}$ sample) was utilized, with $37^{\circ} \mathrm{C}$ static incubation employed to recapitulate conditions of clinical use. OFM-Ag with a nominal ionic silver concentration of $0.30 \pm 0.03 \%$ sustained the majority of ionic silver ( $60 \%)$ over the 7 day elution time course, with the majority of silver elution occurring in the first 3 days of elution (Fig. 3). Given this, the concentration of ionic silver remaining in OFM-Ag after 7 days elution exceeded the determined MEC of $0.15 \pm 0.02 \% \mathrm{w} / \mathrm{w}$ (Fig. 4).

\section{OFM-Ag minimum effective concentration}

Determination of the relationship between antimicrobial concentration and resulting antimicrobial effectiveness informs the minimum amount of antimicrobial required to elicit the desired antimicrobial activity, in this case a $>4$ - $\log$ reduction. The panel of microorganisms used 
for MEC screening encompassed representative gram positive bacteria, gram negative bacteria and fungi. $S$. epidermidis and $P$. aeruginosa were selected as gram positive and negative representatives as both are clinical relevant in the context of wounds as commonly encountered commensals and wound colonizers [83] and have relatively high reported minimum inhibitory concentrations for ionic silver [84]. S. epidermidis in particular has been characterized as highly resilient to inhibition by silver wound dressings [85]. While less common, fungal microorganisms are present in $23 \%$ of chronic wounds with Candida spp. being most prevalent [86] and C. glabrata is reported as less susceptible to inhibition by silver [87]. Results of screening this representative panel indicated the MEC for silver in OFM-Ag to be $0.15 \% \mathrm{w} / \mathrm{w}$ (Fig. 4), or half the nominal concentration of $0.30 \% \mathrm{w} / \mathrm{w}$.

\section{Antimicrobial effectiveness spectrum and wear time}

Based on the derived MEC and silver elution profile of OFM-Ag, a nominal silver concentration of $0.30 \pm 0.03 \%$ $\mathrm{w} / \mathrm{w}$ was selected and OFM-Ag samples of this concentration assessed for antimicrobial effectiveness toward an expanded spectrum of microbial species. Representatives of gram positive bacteria, gram negative bacteria, yeast and mold were included in the spectrum panel, with emphasis on clinical relevance to acute and chronic wounds and including drug-resistant strains which are not only increasingly prevalent in clinical settings but becoming increasingly difficult to treat. The antimicrobial "wear time" or duration of dressing antimicrobial effectiveness of OFM-Ag was assessed as part of this testing by log reduction determination at intervals of 1,3 and 7 days to ascertain the capacity of OFM-Ag to sustain antimicrobial protection over time in simulated use conditions.

Sample hydration, contact time and temperature conditions emulating clinical use are important as such parameters may alter antimicrobial effectiveness, particularly the hydration medium used which may sequester ionic silver. In this study hydration with simulated wound fluid consisting of 50\% serum and 50\% microbiological media was employed to precondition test samples, imitating the protein and electrolyte components of wound fluid which may impinge on the antimicrobial properties of silver. Equally important is neutralization prior to enumerating microbes, otherwise residual antimicrobial carryover may affect microbial growth during enumeration, yielding misleading results. This phenomena was highlighted in false antimicrobial effectiveness results of clinical chlorhexidine preparations when neutralization was not used [88], thus the present assay utilized an ASTM E1054 procedure validated for all species tested.
Generally, gram positive bacteria are considered more resilient to inhibition by silver ions, attributed to the structure of the peptidoglycan rich (negatively charged) gram positive cell wall which sequesters positively charged silver ions, in addition to the cell wall being thicker relative to gram negative bacteria, presenting a greater obstacle to silver ion entry [89]. Four gram positive species were included in the spectrum panel, Staphylococcus aureus (Methicillin-resistant, MRSA), S. epidermidis, Enterococcus faecalis (Vancomycin resistant, VRE) and Streptococcus pyogenes.

Staphylococci are the most prevalent colonizers of human skin and wounded dermal tissues [83]. The drug resistant methicillin-resistant $S$. aureus (MRSA) is a major concern in wound colonization and nosocomial infection, with its prevalence and difficult treatment imparting huge burden to healthcare [90]. S. epidermidis, a common commensal that causes nosocomial infection [91] exhibits high minimum inhibitory concentrations toward ionic silver [84] and resilience to inhibition by silver wound dressings [85]. The gastrointestinal commensal E. faecalis is a common wound pathogen [83] and vancomycin-resistant Enterococci are frequently encountered in clinical environments causing difficult to treat infection, particularly in the United States where VRE prevalence is the highest in the world [92]. S. pyogenes is a typical respiratory, gut and genitourinary commensal and is frequently encountered in skin and soft tissue infections [83] with strains exhibiting $\beta$-haemolytic activity being particularly virulent and invasive [93] and are implicated in necrotizing fasciitis, an uncommon but life-threatening and horrific infection of the skin, underlying soft tissue and muscle [94].

All gram positive species tested were highly susceptible to inactivation by OFM-Ag and antimicrobial effectiveness increasing with contact time (Table 3 ), where the 1 day time point did not achieve complete kill of microbial challenge for MRSA, S. epidermidis or VRE. However, antimicrobial effectiveness was still pronounced toward these organisms at the day 1 time point with log reduction values ranging from $7.0-8.3$ and antimicrobial effectiveness then increasing at days 3 and 7. S. pyogenes was particularly susceptible to OFM-Ag with maximum $\log$ reduction demonstrated at all time points indicating complete kill of the inoculum challenge.

Gram negative species, while generally more susceptible to silver ions due to their cell wall composition, represent a major source of microbial contamination for wounds, dressings and clinical environments. Three species of gram negative bacteria were selected for the spectrum panel, P. aeruginosa, Escherichia coli and Acinetobacter baumannii.

$P$. aeruginosa is an opportunistic pathogen of considerable medical importance being one of the most 
causative species in wound infection [83]. Over 50\% of chronic wounds as colonized by $P$. aeruginosa and its presence is implicated in delays and failure of healing [95]. P. aeruginosa readily forms biofilm and is intrinsically resistant to small molecule inhibitors due to complex arrays of efflux pumps which rapidly clear antimicrobial agents from the bacterial cytosol. E. coli is a well-known coliform bacilli found in the gastrointestinal tract and is the leading cause of gram negative nosocomial infections [96] including skin and soft tissue infections [83]. A. baumannii has recently arisen as a new source of nosocomial infection, with infection rates suddenly spiking during military campaigns in Iraq and Afghanistan, earning the colloquial name "Iraqibacter". The incidence of $A$. baumannii infection in wounded military personnel was thought to be due initial wound contamination associated with the trauma injuries sustained in austere environments. However it is now known $A$. baumannii is primarily transmitted in clinical settings due to surface persistence, resilience to desiccation, resistance to antibiotics and ready person-to-person and fomite transmission [97]. Thus wounded military personnel subject to A. baumannii colonization abroad subsequently spread the organism to support hospitals in Europe and eventually to clinical environments within patient's home countries such as the continental United States [98]. The epidemiology of A. baumannii serves as a stark reminder of how rapidly microorganisms may exploit opportunities to proliferate, even in unwelcoming clinical settings.

Gram negative species were highly susceptible to inhibition by OFM-Ag, with maximum log reduction values of complete inoculum challenge kill achieved toward all species tested at all assay time points (Table 3 ). The presently derived results support that in general gram negative bacteria are more susceptible to inhibition by antimicrobial silver relative to gram positive bacteria.

While bacterial species represent the majority of microbial challenges to wound dressings, to be "antimicrobial" rather than only "antibacterial" demonstration of effectiveness toward fungal microbial species is also required. These eukaryotic microbes are so phylogenetically distinct from bacteria assumptions cannot be made regarding their susceptibility to inhibition by silver dressings. Therefore four species of fungal microorganisms were assessed in the spectrum panel, Candida albicans, Candida glabrata, Candida parapsilosis and Aspergillus brasiliensis (formerly A. niger)

The yeast genus Candida are the most common cause of fungal infections [83] with commensal C. albicans, $C$. parapsilosis and C. glabrata the predominating species opportunistically colonizing wounds [86, 99]. Candida spp. are prevalent in polymicrobial infections and chronic wounds, and these mixed bacterial-fungal biofilms are associated with longer healing times [100]. This makes Candida spp. relevant fungi to wound dressing colonization, particularly C. albicans, C. glabrata and C. parapsilosis.

The present study found that Candida spp. less susceptible to inhibition by ionic silver relative to gram negative bacteria, but more resilient than gram positive bacterial species. Similar to gram positive bacteria, antimicrobial effectiveness toward yeast increased over time with initial $\log$ reduction values of 6.1-7.3 at the 1 day time point, however this rapidly progressed to complete kill at the 3 and 7 day time points for all yeast species tested (Table 3).

Aspergillus is a genus of mold, capable of forming spores which are readily disseminated through the air, Aspergillus spp. are commonly found in soil and water but also air ventilation systems, dust, carpeting, walls and foods. Aspergillus spp. are opportunistic pathogens, particularly affecting patients with risk factors of immunocompromization or diabetes to cause aspergillosis, typically affecting the respiratory tract but also cutaneous infection [101]. Aspergillus spp. are the second most common cause of nosocomial invasive fungal infections, after Candida spp. [102]. A. brasiliensis is reported as highly sensitive to ionic silver with a mode MIC (8 isolate strains) of $0.5 \mu \mathrm{g} / \mathrm{mL} \mathrm{AgNO}_{3}\left(0.32 \mu \mathrm{g} / \mathrm{mL} \mathrm{Ag}^{+}\right)$determined via CLSI microdilution [103]. In comparison, C. parapsilosis has a reported $\mathrm{Ag}^{+}$MIC of $1.69 \mu \mathrm{g} / \mathrm{mL}$ [104]. Therefore it was surprising a $1.8 \log$ reduction toward $A$. brasiliensis was determined at the 1-day time point, however at subsequent 3 and 7 day time points the maximum $>5.3 \mathrm{log}$ reduction was derived (Table 3 ). Prior to 1-day extraction o no visible microbial growth was observed on any OFM-Ag test samples. This apparent discrepancy is attributed to the spore inoculum used for $A$. brasiliensis testing to allow standardization and enumeration of inoculum titre, as institutionally recommended for susceptibility testing of filamentous fungi [105] as liquid cultures exhibit non-homogeneous aggregation [106]. Spores are highly tolerant to chemical and environmental stressors, functioning to disseminate the microorganism and grow when favourable conditions are encountered. In this way, testing $A$. brasiliensis spores represents a clinically relevant worst-case as $A$. brasiliensis colonization is likely to be disseminated as spores. In this testing, it is postulated inoculated spores lay dormant on OFM-Ag through the 1-day contact period and after neutralizing extraction and plating to nutrient rich medium, remaining viable spores germinated. Thus, it is be concluded OFM-Ag was protected from colonization by $A$. brasiliensis during the 1-day incubation as no filamentous mycelial growth was observed and the titre of viable organisms was reduced from that of the inoculum. However, OFM-Ag did not 
sporocidally eradicate the $A$. brasiliensis spore challenge within the 1-day contact period, although interestingly this occurred at the 3 and 7 day time points.

Using a standard and validated test method with parameters representative of clinical wound dressing use OFM-Ag demonstrated antimicrobial effectiveness over a 7-day time period against diverse range of 11 microbial species of relevance in affecting wounds and dressings. This antimicrobial spectrum including yeasts, mold and drug resistant strains is comprehensive relative to that described for commercial silver/collagen wound dressings which are both limited to four bacterial species only. The product insert for collagen/ORC-silver claiming effectiveness toward two gram positive bacteria, $S$. aureus, and S. pyogenes, and two gram negative bacteria, $P$. aeruginosa and E. coli. Product information for the collagen-silver dressing similarly claims antibacterial effectiveness toward two gram positive species, $S$. aureus (MRSA) and S. epidermidis, in addition to two gram negative species $P$. aeruginosa and $E$. coli. No explicit antimicrobial effectiveness wear time duration is described for either commercial silver/collagen dressings is stated, however the reapplication rate described in product information of "daily" and "up to 7 days" for collagen/ORC-silver and collagen-silver dressings, respectively, provides an indication of potential wear time.

Demonstration of antimicrobial effectiveness toward drug resistant strains MRSA and VRE, both being clinically prevalent and difficult to treat $[90,92]$, indicates potential utility of OFM in mitigating infection risks of these drug resistant organisms, and the present results for these drug-resistant variants may be used to infer the susceptibility of their respective non-resistant stains. In preventing colonization, risk of infection is reduced which in turn reduces the need for systemic antibiotic treatment.

As with all antimicrobial agents, development of resistance is always possible. However despite decades of widespread use of antimicrobial silver the occurrence of clinically problematic resistance to silver is extremely low [107] and silver resistance remains predominately confined to laboratory settings and deliberate generation of resistant research strains [108]. OFM-Ag presents negligible risk of microbial resistance, largely attributed to the low resistance potential of ionic silver due to its multimodal mechanism of action [37]. Additionally, lab studies have shown silver resistance development requires prolonged (weeks to months) exposure to sub-lethal concentrations of silver. With an OFM-Ag silver concentration of $0.30 \% \mathrm{w} / \mathrm{w}$, effective microbiocidal action is achieved within 7 days, providing no opportunity for accumulated resistance. Local application of OFM-Ag for tissue regeneration also reduces off-target exposure of antimicrobial silver, unlike systemic antimicrobials which exert selective pressure not only on target pathogens but also large reservoirs of commensal microflora such as the gastrointestinal tract. This combination of silver's mechanism of action, supra-lethal concentration and targeted antimicrobial effect present OFM-Ag as a prudent approach to controlling microbial risk without resistance potential and aligned with antimicrobial stewardship.

\section{Biofilm prevention}

As the incidence of biofilm in chronic wounds is very high [14], associated with complications in healing [11] and very difficult to treat with antimicrobials [109] this is an area of great interest to wound management. Debridement is the primary strategy toward wound biofilm $[17,18]$, but recurrence of biofilm post-debridement may occur [19]. Therefore combining debridement with an antimicrobial control measure to supress biofilm reformation is a key biofilm management strategy [18, 21]. Utilization of an antimicrobial collagen dressing in this way is an efficient approach, providing the antimicrobial effect for preventing biofilm growth in addition to the scaffold of a collagen dressing for wound healing. Therefore, we assessed the effects of OFM-Ag toward preventing biofilm formation in comparison to commercial silver collagen wound dressings and standard compression gauze. Due to the polymicrobial nature of typical wound biofilms [15] we opted for a polymicrobial biofilm model comprising $S$. epidermidis, $P$. aeruginosa and C. glabrata to represent prevalent gram positive/negative bacterial and fungal microbial species found in wounds. The model utilized a naïve biofilm, seeking to replicate in vitro the non-established state of biofilm remnants post-debridement, in order to explore the effects of combining an antimicrobial dressing with debridement.

OFM-Ag demonstrated prevention of polymicrobial biofilm formation to a greater degree than that of commercially available silver wound dressings by a statistically significant margin (Fig. 5). Interestingly, there was no apparent dose-dependent effect of dressing silver concentration and biofilm growth prevention, with the highest silver concentration dressing, collagen-silver $(1.2 \% \mathrm{w} / \mathrm{w} \mathrm{AgCl})$ exhibiting the least biofilm prevention and having no significant difference compared to the non-antimicrobial gauze control. This may be attributed to the form of silver used, with both ionic silver containing test samples, OFM-Ag and collagen/ORC-silver, providing significant prevention of biofilm formation relative to the control. These in vitro results demonstrate that OFM-Ag may be a useful adjunct measure in combination with debridement to control wound biofilm while concurrently providing the beneficial regenerative effects of a dECM. 


\section{Cytotoxicity}

For assessment of the cytotoxic effects of ionic silver, OFM-Ag and commercial silver wound dressings the ISO 10993-5 MTT Cytotoxicity assay was utilized. This method provides a quantitative measure of cell viability based on the metabolic activity of viable cells which reduces MTT reagent to formazan that may be colorimetrically measured. For baseline characterization purposes the cytotoxicity dose response of ionic silver toward mammalian fibroblasts was established. Results for $\mathrm{Ag}^{+}$ cytotoxicity characterization of $\mathrm{IC}_{50}$ value of $0.774 \mu \mathrm{g} /$ $\mathrm{mL}$ and a maximum non-cytotoxic concentration $(>70 \%$ cell viability) of $0.50 \mu \mathrm{g} / \mathrm{mL}$ (Fig. 6a) are in agreement with previously published $\mathrm{Ag}^{+}$fibroblast cytotoxicity data of $3 \mathrm{~T} 3$ cell $\mathrm{IC}_{50}$ of $25.5 \mu \mathrm{M}$ for $\mathrm{Ag}^{+}(2.75 \mu \mathrm{g} / \mathrm{mL})$ based on succinic dehydrogenase activity [110] and L929 cell $\mathrm{IC}_{50}$ of $4.25 \mu \mathrm{M}$ for $\mathrm{AgNO}_{3}\left(0.46 \mu \mathrm{g} / \mathrm{mL} \mathrm{Ag}^{+}\right)$based on differential staining [111]. Similarly, ionic silver has demonstrated toxicity at $2.5 \mu \mathrm{g} / \mathrm{mL}$ toward human mesenchymal stem cells, $1 \mu \mathrm{g} / \mathrm{mL}$ for human monocytes and $1.5 \mu \mathrm{g} / \mathrm{mL}$ for human T-cells [112, 113]. Considering the presently derived results and supporting literature, $\mathrm{Ag}^{+}$ is readily cytotoxic in vitro to mammalian fibroblasts and other cell types involved in wound healing.

The effects of commercial collagen-silver wound dressings containing either high (collagen-silver dressing, $1.2 \% \mathrm{w} / \mathrm{w} \mathrm{AgCl}$ ) or low concentrations of silver (collagen/ORC-silver, $0.25 \% \mathrm{w} / \mathrm{w}$ ionic silver) toward cell viability was assessed to determine if collagen, the primary component of these dressings and OFM-Ag, imparts protective effects toward silver cytotoxicity. OFM-Ag at a nominal silver concentration of $0.30 \% \mathrm{w} / \mathrm{w}$ was included in the same assay for comparison.

Both commercial collagen/ORC-silver and collagen-silver dressings exhibited a clear cytotoxic response (Fig. 6b). While this may be expected of the dressing with the highest silver concentration, collagen-silver $(1.2 \% \mathrm{w} / \mathrm{w} \mathrm{AgCl}$, equivalent to $\sim 0.9 \% \mathrm{w} / \mathrm{w} \mathrm{Ag}$ ), it is interesting that collagen/ORC-silver which contains the lowest concentration of silver $(0.25 \% \mathrm{w} / \mathrm{w}$ ionic silver) was also cytotoxic. In contrast, OFM-Ag $(0.30 \%$ w/w Ag) demonstrated no cytotoxicity. The relative cytotoxicity of the three test samples remained unchanged with differing incubation time periods (e.g. $24 \mathrm{~h}$ vs $48 \mathrm{~h}$ )(data not shown).

Differences between the three test samples may be attributed to the base material. While OFM is an intact ECM bioscaffold, both collagen/ORC-silver and collagen-silver dressings comprise a reconstituted collagen. One consequence of this is that both products "gel" on contact with would fluid, as described in the relevant product inserts. This rapid "gelling" and disintegration of the reconstituted dressings on contact with aqueous rehydration solution or wound fluid may produce an initial transient bolus of silver release resulting in the observed cytotoxic response.

While the low cytotoxicity potential of OFM-Ag is likely to be predominately attributed to the release kinetics of $\mathrm{Ag}^{+}$from the material, other mechanisms may contribute as it is established that biological compounds modulate the cytotoxicity of silver [114]. OFM material is comprised of not only collagens, but a complex heterogeneous mixture of ECM secondary molecules such as structural proteins, proteoglycans, glycoproteins and growth factors [48] which have evidence of protective effects toward silver cytotoxicity. For example, growth factors have shown to mitigate the in vitro cytotoxicity and in vivo wound healing impairment caused by silver sulfadiazine $[115,116]$. Fibronectin has demonstrated to attenuate the impact of silver sulfadiazine toward fibroblast proliferation [117]. Hyaluronic acid in combination with silver sulfadiazine significantly expedites re-epithelization of burn wounds compared to silver sulfadiazine alone [118]. Considering the sulfonamide component of silver sulfadiazine is non-cytotoxic [119] the cytoprotective effects of these ECM secondary molecules is presumably directed toward mitigating silver toxicity. While the relationship between these OFM components and alleviation of silver cytotoxicity is not yet established, the present results indicate that functionalization of a AECM material with silver confers a more advantageous cytotoxicity profile relative to silver containing collagen dressings.

\section{Conclusion}

Characterization of OFM-Ag has demonstrated that functionalization of a $\mathrm{dECM}$ material with ionic silver may be achieved to confer broad spectrum antimicrobial effectiveness and suppression of biofilm formation while retaining the intrinsic ECM composition and structural properties beneficial to healing and resolving wound chronicity. The sustained duration and wide spectrum of antimicrobial effectiveness and non-cytotoxic properties characterized OFM-Ag relative to existing collagen dressings containing silver is proposed to be attributed to the preserved heterogeneous $\mathrm{AECM}$ material, which confers differential binding and sustained release of silver from the material relative to rapidly disintegrating reconstituted collagen substrates. As cytotoxicity is a well-known caveat of silver containing wound dressings, this presents OFM-Ag as a useful biomaterial in the management of acute and chronic wounds of high microbial risk, imparting sustained antimicrobial effectiveness without cytotoxic effects detrimental to healing.

\section{Abbreviations}

AAS: Atomic absorption spectroscopy; BHI: Brain-heart infusion; CFU: Colony forming unit; dECM: Decellularized extracellular matrix; DMAB: 4-

(dimethylamino)benzaldehyde; DMEM: Dulbecco's minimal essential media; 
DSC: Differential scanning calorimetry; ECM: Extracellular matrix; FCS: Fetal calf serum; GAG: Glycosaminoglycan; H\&E: Hematoxylin and eosin; $\mathrm{IC}_{50}$ : 50\% inhibitory concentration; MEC: Minimum effective concentration; MRSA: Methicillin resistant S. aureus; MTT: 3-(4,5-dimethylthiazol-2-yl)-2,5diphenyltetrazolium bromide; OFM: Ovine forestomach matrix; OFMAg: Silver-functionalized ovine forestomach matrix; OFT: Ovine forestomach tissue; ORC: Oxidized regenerated cellulose; PBS: Phosphate buffered saline; $\mathrm{ROH}_{2} \mathrm{O}$ : Reverse osmosis purified water; SDB: Sabouraud dextrose broth; SEM: Scanning electron microscopy; SWF: Simulated wound fluid; $T_{m}$ : Onset melt temperature; TSB: Tryptic soy broth; VRE: Vancomycin resistant Enterococci

\section{Acknowledgements}

Not applicable.

\section{Funding}

This work was funded by Aroa Biosurgery Ltd. and Callaghan Innovation Limited (New Zealand) Growth Grant (MSMA1402).

\section{Availability of data and materials}

Data generated and analysed during the current study is available from the corresponding author on reasonable request.

\section{Authors' contributions}

CHM and BCHM designed the research. AN, RR and SGD performed material characterization. TK performed antimicrobial effectiveness testing. MJ performed elution kinetics and biofilm testing. SGD performed cytotoxicity testing. CHM prepared the manuscript. All authors analysed experimental data and approved the final manuscript.

\section{Ethics approval and consent to participate}

Not applicable.

\section{Consent for publication}

Not applicable.

\section{Competing interests}

All authors are employees of Aroa Biosurgery Ltd. BCHM, CHM, TK, MJ, and AN are shareholders in Aroa Biosurgery Ltd.

\section{Publisher's Note}

Springer Nature remains neutral with regard to jurisdictional claims in published maps and institutional affiliations.

\section{Received: 12 November 2018 Accepted: 6 February 2019} Published online: 22 February 2019

\section{References}

1. McCann MT, Gilmore BF, Gorman SP. Staphylococcus epidermidis devicerelated infections: pathogenesis and clinical management. J Pharm Pharmacol. 2008;60:1551-71.

2. Howell-Jones R, Wilson M, Hill K, Howard A, Price P, Thomas D. A review of the microbiology, antibiotic usage and resistance in chronic skin wounds. J Antimicrob Chemother. 2005:55:143-9.

3. Wolcott RD, Hanson JD, Rees EJ, Koenig LD, Phillips CD, Wolcott RA, Cox SB, White JS. Analysis of the chronic wound microbiota of 2,963 patients by $16 \mathrm{~S}$ rDNA pyrosequencing. Wound Repair Regen. 2016;24:163-74.

4. Trafny EA, Kowalska K, Grzybowski J. Adhesion of Pseudomonas aeruginosa to collagen biomaterials: effect of amikacin and ciprofloxacin on the colonization and survival of the adherent organisms. Journal of Biomedical Materials Research: An Official Journal of The Society for Biomaterials, The Japanese Society for Biomaterials, and the Australian Society for Biomaterials. 1998;41:593-9.

5. Lee JE, Park JC, Hwang YS, Kim JK, Kim JG, Suh H. Characterization of UVirradiated dense/porous collagen membranes: morphology, enzymatic degradation, and mechanical properties. Yonsei Med J. 2001;42:172-9.

6. Madsen SM, Westh H, Danielsen L, Rosdahl VT. Bacterial colonization and healing of venous leg ulcers. APMIS. 1996;104:895-9.

7. Stadelmann WK, Digenis AG, Tobin GR. Impediments to wound healing. Am J Surg. 1998;176:39S-47S.
8. Browne AC, Vearncombe M, Sibbald RG. High bacterial load in asymptomatic diabetic patients with neurotrophic ulcers retards wound healing after application of Dermagraft. Ostomy Wound Manage. 2001;47: 44-9.

9. Costerton JW, Stewart PS, Greenberg EP. Bacterial biofilms: a common cause of persistent infections. Science. 1999;284:1318-22.

10. Wolcott RD, Rhoads DD, Dowd SE. Biofilms and chronic wound inflammation. J Wound Care. 2008;17:333-41.

11. Metcalf DG, Bowler PG. Biofilm delays wound healing: a review of the evidence. Burns \& Trauma. 2013;1:5

12. Church D, Elsayed S, Reid O, Winston B, Lindsay R. Burn wound infections. Clin Microbiol Rev. 2006;19:403-34.

13. Roy S, Elgharably H, Sinha M, Ganesh K, Chaney S, Mann E, Miller C, Khanna S, Bergdall VK, Powell HM. Mixed-species biofilm compromises wound healing by disrupting epidermal barrier function. J Pathol. 2014;233:331-43.

14. Malone M, Bjarnsholt T, McBain AJ, James GA, Stoodley P, Leaper D, Tachi M, Schultz G, Swanson T, Wolcott RD. The prevalence of biofilms in chronic wounds: a systematic review and meta-analysis of published data. J Wound Care. 2017:26:20-5.

15. James GA, Swogger E, Wolcott R, DeLancey Pulcini E, Secor P, Sestrich J, Costerton JW, Stewart PS. Biofilms in chronic wounds. Wound Repair Regen. 2008; 16:37-44

16. Percival SL, Malone M, Mayer D, Salisbury AM, Schultz G. Role of anaerobes in polymicrobial communities and biofilms complicating diabetic foot ulcers. International wound journal. 2018.

17. Wolcott R, Kennedy J, Dowd S. Regular debridement is the main tool for maintaining a healthy wound bed in most chronic wounds. J Wound Care. 2009:18:54-6.

18. Schultz G, Bjarnsholt T, James GA, Leaper DJ, McBain AJ, Malone M, Stoodley P, Swanson T, Tachi M, Wolcott RD. Consensus guidelines for the identification and treatment of biofilms in chronic nonhealing wounds. Wound Repair Regen. 2017;25:744-57.

19. Wolcott R, Rumbaugh K, James G, Schultz G, Phillips P, Yang Q, Watters C, Stewart PS, Dowd S. Biofilm maturity studies indicate sharp debridement opens a time-dependent therapeutic window. J Wound Care. 2010;19:3208.

20. Omar A, Wright JB, Schultz G, Burrell R, Nadworny P. Microbial biofilms and chronic wounds. Microorganisms. 2017;5:9.

21. Leaper DJ, Schultz G, Carville K, Fletcher J, Swanson T, Drake R. Extending the TIME concept: what have we learned in the past 10 years? Int Wound J. 2012;9:1-19.

22. Bowler P, Duerden B, Armstrong DG. Wound microbiology and associated approaches to wound management. Clin Microbiol Rev. 2001;14:244-69.

23. Cutting KF, White R. Defined and refined: criteria for identifying wound infection revisited. British journal of community nursing. 2004:9:S6-S15.

24. Posnett J, Franks P. The burden of chronic wounds in the UK. Diabetic Med. 2008:14:57-S85.

25. Margolis DJ, Allen-Taylor L, Hoffstad O, Berlin JA. Diabetic neuropathic foot ulcers: the association of wound size, wound duration, and wound grade on healing. Diabetes Care. 2002;25:1835-9.

26. Jeffcoate WJ, Harding KG. Diabetic foot ulcers. Lancet. 2003:361:1545-51.

27. Pecoraro RE, Reiber GE, Burgess EM. Pathways to diabetic limb amputation: basis for prevention. Diabetes Care. 1990;13.5:513-21. https://doi.org/10. 2337/diacare.13.5.513.

28. Sergent A-P, Slekovec C, Pauchot J, Jeunet L, Bertrand X, Hocquet D, Pazart $L$, Talon D. Bacterial contamination of the hospital environment during wound dressing change. Orthopaedics \& Traumatology: Surgery \& Research 2012;98:441-5.

29. Bache SE, Maclean M, Gettinby G, Anderson JG, MacGregor SJ, Taggart I. Airborne bacterial dispersal during and after dressing and bed changes on burns patients. Burns. 2015;41:39-48.

30. Edwards-Jones $V$. The benefits of silver in hygiene, personal care and healthcare. Lett Appl Microbiol. 2009;49:147-52.

31. Melaiye A, Youngs WJ. Silver and its application as an antimicrobial agent: Taylor \& Francis; 2005

32. Lansdown AB: Silver in health care: antimicrobial effects and safety in use. In Biofunctional textiles and the skin. Volume 33: Karger Publishers; 2006: 17-34

33. Percival SL, Bowler P, Russell D. Bacterial resistance to silver in wound care. Hosp Infect. 2005;60:1-7.

34. Holt KB, Bard AJ. Interaction of silver (I) ions with the respiratory chain of Escherichia coli: an electrochemical and scanning electrochemical 
microscopy study of the antimicrobial mechanism of micromolar ag+ Biochemistry. 2005;44:13214-23.

35. Dibrov P, Dzioba J, Gosink KK, Häse CC. Chemiosmotic mechanism of antimicrobial activity of ag+ in Vibrio cholerae. Antimicrob Agents Chemother. 2002;46:2668-70.

36. Banin E, Hughes D, Kuipers OP. Bacterial pathogens, antibiotics and antibiotic resistance. FEMS Microbiol Rev. 2017;41:450-2.

37. Bowler PG. Antibiotic resistance and biofilm tolerance: a combined threat in the treatment of chronic infections. J Wound Care. 2018;27:273-7.

38. Wright JB, Lam K, Burrell RE. Wound management in an era of increasing bacterial antibiotic resistance: a role for topical silver treatment. Am J Infect Control. 1998;26:572-7.

39. Poon VK, Burd A. In vitro cytotoxity of silver: implication for clinical wound care. Burns. 2004;30:140-7.

40. Burd A, Kwok CH, Hung SC, Chan HS, Gu H, Lam WK, Huang L. A comparative study of the cytotoxicity of silver-based dressings in monolayer cell, tissue explant, and animal models. Wound Repair Regen. 2007;15:94-104.

41. Rosen J, Landriscina A, Kutner A, Adler BL, Krausz AE, Nosanchuk JD, Friedman AJ. Silver sulfadiazine retards wound healing in mice via alterations in cytokine expression. J Investig Dermatol. 2015;135:1459-62.

42. Hidalgo E, Domınguez C. Study of cytotoxicity mechanisms of silver nitrate in human dermal fibroblasts. Toxicol Lett. 1998;98:169-79.

43. Chattopadhyay S, Raines RT. Review collagen-based biomaterials for wound healing. Biopolymers. 2014;101:821-33.

44. Hoshiba T, Lu H, Kawazoe N, Chen G. Decellularized matrices for tissue engineering. Expert Opin Biol Ther. 2010;10:1717-28.

45. Badylak SF. Xenogeneic extracellular matrix as a scaffold for tissue reconstruction. Transpl Immunol. 2004;12:367-77.

46. Tracy LE, Minasian RA, Caterson E. Extracellular matrix and dermal fibroblast function in the healing wound. Advances in wound care. 2016;5:119-36.

47. Fleck CA, Simman R. Modern collagen wound dressings: function and purpose. The Journal of the American College of Certified Wound Specialists. 2010;2:50-4

48. Lun S, Irvine SM, Johnson KD, Fisher NJ, Floden EW, Negron L, Dempsey SG, McLaughlin RJ, Vasudevamurthy M, Ward BR. A functional extracellular matrix biomaterial derived from ovine forestomach. Biomaterials. 2010;31: 4517-29.

49. Sizeland KH, Wells HC, Kelly SJ, Nesdale KE, May BC, Dempsey SG, Miller CH, Kirby N, Hawley A, Mudie S. Collagen fibril response to strain in scaffolds from ovine forestomach for tissue engineering. ACS Biomaterials Science \& Engineering. 2017;3:2550-8.

50. Irvine SM, Cayzer J, Todd EM, Lun S, Floden EW, Negron L, Fisher JN, Dempsey SG, Alexander A, Hill MC. Quantification of in vitro and in vivo angiogenesis stimulated by ovine forestomach matrix biomaterial. Biomaterials. 2011;32:6351-61.

51. Bohn GA, Gass K. Leg ulcer treatment outcomes with new ovine collagen extracellular matrix dressing: a retrospective case series. Adv Skin Wound Care. 2014;27:448-54.

52. Liden BA, May BC. Clinical outcomes following the use of ovine forestomach matrix (endoform dermal template) to treat chronic wounds. Adv Skin Wound Care. 2013;26:164-7.

53. Simcock J, May BC. Ovine forestomach matrix as a substrate for single-stage split-thickness graft reconstruction. Eplasty. 2013;13.

54. Gould L. Topical collagen-based biomaterials for chronic wounds: rationale and clinical application. Advances in wound care. 2016;5:19-31.

55. Bohn G, Liden B, Schultz G, Yang Q, Gibson DJ. Ovine-based collagen matrix dressing: next-generation collagen dressing for wound care. Advances in wound care. 2016;5:1-10.

56. Zhong S, Zhang Y, Lim C. Tissue scaffolds for skin wound healing and dermal reconstruction. Wiley Interdisciplinary Reviews: Nanomedicine and Nanobiotechnology. 2010;2:510-25.

57. López Alonso M, Benedito J, Miranda M, Castillo C, Hernandez J, Shore R. Toxic and trace elements in liver, kidney and meat from cattle slaughtered in Galicia (NW Spain). Food Additives \& Contaminants. 2000;17:447-57.

58. Edwards C, O'Brien W Jr. Modified assay for determination of hydroxyproline in a tissue hydrolyzate. Clin Chim Acta. 1980;104:161-7.

59. Neuman RE, Logan MA. The determination of collagen and elastin in tissues. J Biol Chem. 1950;186:549-56.

60. Freytes DO, Martin J, Velankar SS, Lee AS, Badylak SF. Preparation and rheological characterization of a gel form of the porcine urinary bladder matrix. Biomaterials. 2008;29:1630-7.
61. O'Toole GA. Microtiter dish biofilm formation assay. JoVE: Journal of visualized experiments; 2011.

62. Dini V, Salvo P, Janowska A, Di FF, Barbini A, Romanelli M. Correlation between wound temperature obtained with an infrared camera and clinical wound bed score in venous leg ulcers. Wounds: a compendium of clinical research and practice. 2015;27:274-8.

63. Aamodt JM, Grainger DW. Extracellular matrix-based biomaterial scaffolds and the host response. Biomaterials. 2016;86:68-82.

64. Hussey GS, Dziki JL, Badylak SF. Extracellular matrix-based materials for regenerative medicine. Nature Reviews Materials. 2018;1.

65. Negron L, Lun S, May BC. Ovine forestomach matrix biomaterial is a broad spectrum inhibitor of matrix metalloproteinases and neutrophil elastase. Int Wound J. 2014;11:392-7.

66. Jackson RL, Busch SJ, Cardin AD. Glycosaminoglycans: molecular properties, protein interactions, and role in physiological processes. Physiol Rev. 1991; 71:481-539.

67. Hodde JP, Badylak SF, Brightman AO, Voytik-Harbin SL. Glycosaminoglycan content of small intestinal submucosa: a bioscaffold for tissue replacement. Tissue Eng. 1996;2:209-17.

68. Schenke-Layland K, Vasilevski O, Opitz F, König K, Riemann I, Halbhuber K, Wahlers T, Stock U. Impact of decellularization of xenogeneic tissue on extracellular matrix integrity for tissue engineering of heart valves. J Struct Biol. 2003;143:201-8.

69. Partington L, Mordan N, Mason C, Knowles J, Kim H, Lowdell M, Birchall $\mathrm{M}$, Wall I. Biochemical changes caused by decellularization may compromise mechanical integrity of tracheal scaffolds. Acta Biomater. 2013;9:5251-61.

70. Reing JE, Brown BN, Daly KA, Freund JM, Gilbert TW, Hsiong SX, Huber A, Kullas KE, Tottey S, Wolf MT. The effects of processing methods upon mechanical and biologic properties of porcine dermal extracellular matrix scaffolds. Biomaterials. 2010;31:8626-33.

71. Cornwell KG, Landsman A, James KS. Extracellular matrix biomaterials for soft tissue repair. Clin Podiatr Med Surg. 2009;26:507-23.

72. Rennert RC, Sorkin M, Garg RK, Januszyk M, Gurtner GC. Cellular response to a novel fetal acellular collagen matrix: implications for tissue regeneration. International journal of biomaterials. 2013;2013.

73. Badylak SF, Freytes DO, Gilbert TW. Extracellular matrix as a biological scaffold material: structure and function. Acta Biomater. 2009;5:1-13.

74. Sun WQ, Xu H, Sandor M, Lombardi J. Process-induced extracellular matrix alterations affect the mechanisms of soft tissue repair and regeneration. Journal of tissue engineering. 2013;4:2041731413505305.

75. Sun WQ, Leung P. Calorimetric study of extracellular tissue matrix degradation and instability after gamma irradiation. Acta Biomater. 2008;4:817-26.

76. Miles CA, Avery NC, Rodin W, Bailey AJ. The increase in denaturation temperature following cross-linking of collagen is caused by dehydration of the fibres. J Mol Biol. 2005;346:551-6.

77. Melling M, Pfeiler W, Karimian-Teherani D, Schnallinger M, Sobal G, Zangerle C, Menzel EJ. Differential scanning calorimetry, biochemical, and biomechanical analysis of human skin from individuals with diabetes mellitus. Anat Rec. 2000;259:327-33.

78. Tang R, Samouillan V, Dandurand J, Lacabanne C, Nadal-Wollbold F, Casas C, Schmitt A-M. Thermal and vibrational characterization of human skin. J Therm Anal Calorim. 2017;127:1143-54.

79. Sacopulos AM, Sherman DM, Janis AD. Preservation of native extracellular matrix structure correlates with onset temperature in eight commercial collagen wound dressings. In: Front Bioeng Biotechnol Conference Abstract: 10th World Biomaterials Congress; 2016.

80. Godard P, Biebuyck J-J, Daumerie M, Naveau H, Mercier J. Crystallization and melting of aqueous gelatin. J Polym Sci Polym Phys Ed. 1978;16:1817-28.

81. Kaminski A. Determination of silver release from wound care products master of science thesis in materials chemistry and nanotechnology; 2013.

82. Dealey C, Cameron J, Arrowsmith M. A study comparing two objective methods of quantifying the production of wound exudate. J Wound Care. 2006;15:149-53.

83. Solanki R, Nagori B. A review on microorganisms causing wound infections on skin. Asian Journal of Pharmacy and Technology. 2013;3:119-22.

84. Pal S, Yoon EJ, Park SH, Choi EC, Song JM. Metallopharmaceuticals based on silver (I) and silver (II) polydiguanide complexes: activity against burn wound pathogens. J Antimicrob Chemother. 2010;65:2134-40.

85. Ziegler K, Görl R, Effing J, Ellermann J, Mappes M, Otten S, Kapp H, Zoellner $\mathrm{P}$, Spaeth D, Smola H. Reduced cellular toxicity of a new silver-containing 
antimicrobial dressing and clinical performance in non-healing wounds. Skin Pharmacol Physiol. 2006;19:140-6.

86. Dowd S, Delton Hanson J, Rees E, Wolcott R, Zischau A, Sun Y, White J, Smith D, Kennedy J, Jones C. Survey of fungi and yeast in polymicrobial infections in chronic wounds. J Wound Care. 2011;20:40-7.

87. Monteiro D, Gorup L, Silva S, Negri M, de Camargo E, Oliveira R, DdB B, Henriques M. Silver colloidal nanoparticles: antifungal effect against adhered cells and biofilms of Candida albicans and Candida glabrata Biofouling, vol. 27; 2011. p. 711-9.

88. Kampf G, Shaffer M, Hunte C. Insufficient neutralization in testing a chlorhexidine-containing ethanol-based hand rub can result in a false positive efficacy assessment. BMC Infect Dis. 2005;5:48.

89. Kawahara K, Tsuruda K, Morishita M, Uchida M. Antibacterial effect of silverzeolite on oral bacteria under anaerobic conditions. Dent Mater. 2000;16:452-5.

90. Klevens RM, Morrison MA, Nadle J, Petit S, Gershman K, Ray S, Harrison LH, Lynfield R, Dumyati G, Townes JM. Invasive methicillin-resistant Staphylococcus aureus infections in the United States. JAMA. 2007;298: 1763-71.

91. Vuong C, Otto M. Staphylococcus epidermidis infections. Microbes Infect. 2002:4:481-9.

92. O'Driscoll T, Crank CW. Vancomycin-resistant enterococcal infections: epidemiology, clinical manifestations, and optimal management. Infection and drug resistance. 2015;8:217.

93. Nizet V. Streptococcal $\beta$-hemolysins: genetics and role in disease pathogenesis. Trends Microbiol. 2002;10:575-80.

94. Misiakos EP, Bagias G, Patapis P, Sotiropoulos D, Kanavidis P, Machairas A. Current concepts in the management of necrotizing fasciitis. Frontiers in surgery. 2014;1:36.

95. Bjarnsholt T, Kirketerp-Møller K, Jensen Pø, Madsen KG, Phipps R, Krogfelt K, Høiby N, Givskov M. Why chronic wounds will not heal: a novel hypothesis. Wound Repair Regen. 2008;16:2-10

96. Weinstein RA, Gaynes R, Edwards JR, System NNIS. Overview of nosocomial infections caused by gram-negative bacilli. Clin Infect Dis. 2005;41:848-54.

97. Urban C, Segal-Maurer S, Rahal JJ. Considerations in control and treatment of nosocomial infections due to multidrug-resistant Acinetobacter baumannii. Clin Infect Dis. 2003;36:1268-74.

98. Howard A, O'Donoghue M, Feeney A, Sleator RD. Acinetobacter baumannii: an emerging opportunistic pathogen. Virulence. 2012;3:243-50.

99. Fidel PL, Vazquez JA, Sobel JD. Candida glabrata: review of epidemiology, pathogenesis, and clinical disease with comparison toC. Albicans. Clin Microbiol Rev. 1999;12:80-96.

100. Harriott MM, Noverr MC. Importance of Candida-bacterial polymicrobial biofilms in disease. Trends Microbiol. 2011;19:557-63.

101. Mohapatra S, Xess I, Swetha J, Tanveer N, Asati D, Ramam M, Singh M. Primary cutaneous aspergillosis due to Aspergillus Niger in an immunocompetent patient. Indian J Med Microbiol. 2009;27:367.

102. Perlroth J, Choi B, Spellberg B. Nosocomial fungal infections: epidemiology, diagnosis, and treatment. Med Mycol. 2007;45:321-46.

103. Xu Y, Pang G, Gao C, Zhao D, Zhou L, Sun S, Wang B. In vitro comparison of the efficacies of natamycin and silver nitrate against ocular fungi. Antimicrob Agents Chemother. 2009;53:1636-8.

104. Kvitek L, Panacek A, Prucek R, Soukupova J, Vanickova M, Kolar M, Zboril R: Antibacterial activity and toxicity of silver-nanosilver versus ionic silver. In Journal of Physics: Conference Series. IOP Publishing;2011: 012029.

105. Petrikkou E, Rodrıguez-Tudela JL, Cuenca-Estrella M, Gómez A, Molleja A, Mellado E. Inoculum standardization for antifungal susceptibility testing of filamentous fungi pathogenic for humans. J Clin Microbiol. 2001;39:1345-7.

106. Van Veluw G, Teertstra W, De Bekker C, Vinck A, Van Beek N, Muller W, Arentshorst M, van der Mei H, Ram A, Dijksterhuis J. Heterogeneity in liquid shaken cultures of Aspergillus Niger inoculated with melanised conidia or conidia of pigmentation mutants. Stud Mycol. 2013;74:47-57.

107. Finley PJ, Norton R, Austin C, Mitchell A, Zank S, Durham P. Unprecedented silver-resistance in clinically isolated Enterobacteriaceae: Major implications for burn and wound management. Antimicrobial agents and chemotherapy. 2015:AAC. 00026-00015.

108. Li X-Z, Nikaido H, Williams KE. Silver-resistant mutants of Escherichia coli display active efflux of ag+ and are deficient in porins. J Bacteriol. 1997;179: 6127-32.

109. Percival SL, Hill KE, Malic S, Thomas DW, Williams DW. Antimicrobial tolerance and the significance of persister cells in recalcitrant chronic wound biofilms. Wound Repair Regen. 2011;19:1-9.
110. Wataha JC, Hanks CT, Sun Z. Effect of cell line on in vitro metal ion cytotoxicity. Dent Mater. 1994;10:156-61.

111. Yamamoto A, Honma R, Sumita M. Cytotoxicity evaluation of 43 metal salts using murine fibroblasts and osteoblastic cells. Journal of Biomedical Materials Research: An Official Journal of The Society for Biomaterials, The Japanese Society for Biomaterials, and the Australian Society for Biomaterials. 1998;39:331-40.

112. Greulich C, Braun D, Peetsch A, Diendorf J, Siebers B, Epple M, Köller M. The toxic effect of silver ions and silver nanoparticles towards bacteria and human cells occurs in the same concentration range. RSC Adv. 2012;2:6981-7.

113. Chernousova S, Epple M. Silver as antibacterial agent: ion, nanoparticle, and metal. Angew Chem Int Ed. 2013;52:1636-53.

114. Mulley G, Jenkins ATA, Waterfield NR. Inactivation of the antibacterial and cytotoxic properties of silver ions by biologically relevant compounds. PLoS One. 2014;9:e94409.

115. McCauley RL, Li Y-Y, Chopra V, Herndon DN, Robson MC. Cytoprotection of human dermal fibroblasts against silver sulfadiazine using recombinant growth factors. J Surg Res. 1994;56:378-84.

116. Lee A-RC, Leem H, Lee J, Park KC. Reversal of silver sulfadiazine-impaired wound healing by epidermal growth factor. Biomaterials. 2005;26:4670-6.

117. Mohseni M, Shamloo A, Aghababaei Z, Vossoughi M, Moravvej H. Antimicrobial wound dressing containing silver sulfadiazine with high biocompatibility: in vitro study. Artif Organs. 2016;40:765-73.

118. Costagliola M, Agrosi M. Second-degree burns: a comparative, multicenter, randomized trial of hyaluronic acid plus silver sulfadiazine vs. silver sulfadiazine alone. Current medical research and opinion. 2005;21:1235-40.

119. Zessel K, Mohring S, Hamscher G, Kietzmann M, Stahl J. Biocompatibility and antibacterial activity of photolytic products of sulfonamides. Chemosphere. 2014:100:167-74.

Ready to submit your research? Choose BMC and benefit from

- fast, convenient online submission

- thorough peer review by experienced researchers in your field

- rapid publication on acceptance

- support for research data, including large and complex data types

- gold Open Access which fosters wider collaboration and increased citations

- maximum visibility for your research: over $100 \mathrm{M}$ website views per year

At BMC, research is always in progress.

Learn more biomedcentral.com/submissions 